\title{
More unequal or less? A review of global, regional and national income inequality
}

\author{
Verónica Amarante and Maira Colacce
}

\begin{abstract}
This article presents a multi-perspective discussion of trends in income inequality. Recent evidence from many sources shows that global income inequality is high and relatively stable, with the main changes being driven by developments in China and India. In developed countries, the trend has been towards higher levels of inequality over the last thirty years; and this has also been true of developing countries in the past decade, with the exception of Latin America, which is analysed here in detail. In the region, income became less unevenly distributed between 2002 and 2014, mainly because inequality within countries declined in most cases; but the latest measurements suggest that this trend is faltering.
\end{abstract}

\section{Keywords}

Economic growth, income, income distribution, equality, measurement, developed countries, developing countries, China, Latin America

\section{JEL classification}

D31, D61

\section{Authors}

Verónica Amarante is Chief of the Office of the Economic Commission for Latin America and the Caribbean (ECLAC) in Montevideo. Email: verónica.amarante@cepal.org.

Maira Colacce is a consultant with the ECLAC office in Montevideo. Email: maira. colacce@gmail.com. 


\section{Introduction}

An apparently simple question, which has been posed several times in various fields, is whether economic inequality is greater in our days than it was a few decades ago. In other words: are modern societies becoming more economically equal, or are individual living standards increasingly tending to diverge? Answering a question of this magnitude is complex, and it needs to be approached from different angles to obtain a comprehensive and concrete response. This article seeks to provide inputs to this endeavour, by summarizing recent evidence from various international studies on the subject and delving deeper into specific aspects on which new evidence is presented. To that end, the article draws on a variety of sources, although individual inequality, of either income or consumption, is always analysed on the basis of household surveys. This means ignoring other approaches, such as the inequality of wealth, or other data sources that make it possible to identify the incomes of the wealthiest people with greater precision.

The article starts by reviewing the evidence on the status and trend of global inequality, which entails considering the income or consumption of all individuals in the world as if there were no political boundaries between countries. As differences between individuals arise from inequality both between countries and within them, the study is complemented by a discussion of national experiences. Here a distinction is made between the evolution of inequality in developed and developing countries, since the respective trends have diverged in recent years. Among developing countries, the situation of China is considered in greater detail, since it has a huge influence on global inequality as well as a national trend with interesting specifics. Lastly, the article makes an in-depth analysis of the situation in Latin America, both as a whole and in terms of its individual countries, where inequality mostly declined in the last decade, in contrast to the trend in the developed world. Nonetheless, the latest available data suggests that this process may have reached a plateau. The article's ultimate objective is to present an up-to-date and wide-ranging discussion on income inequality, seeking to provide a general overview of the global and regional situation. The analysis considers different time periods: in the case of global inequality and that of both developing and developed countries, it embraces the entire period covered by the revised bibliography, while the regional analysis focuses on the last decade, during which the previously rising trend of inequality has reversed.

\section{Global inequality}

As economies become more integrated, factors of production increasingly cross borders, and the perceptions and aspirations of the population of each country are increasingly influenced by living standards elsewhere. All of these factors make differences beyond national borders more salient and thus arouse concern for inequality among all inhabitants of the world. The literature on global inequality originally responded to the need to assess the extent to which globalization may have reduced differences between individuals around the world, if the poorest (and most heavily populated) countries had grown faster than the richest (and least populated), despite generating greater inequality within countries. These studies also set out to analyse whether the rules governing the interactions between rich and poor countries affect global inequality.

Although there are several reasons for studying global inequality, Anand and Segal (2008), draw attention to moral or ethical arguments, since disparities between individual incomes around the world can be considered unfair; and this lays the foundations for measuring differences in income between individuals globally rather than by nationality. Secondly, global inequality can explain certain phenomena, such as international migration or bargaining power in international institutions. Lastly, 
global inequality trends are useful for analysing the predictive power of certain theories. For example, neoclassical growth theory predicts that incomes will converge in the long run between countries, and even between individuals, whereas dependency theory predicts divergence.

Before pursuing the analysis, it is important to distinguish between the different concepts of global inequality that are discussed in the literature, to understand their implications and uses. Milanovic (2005) and Anand and Segal (2008) define four concepts of inequality worldwide, based on the elements considered: the units of analysis (countries or persons), the unit of measurement (total, per capita or household income), and the weighting of the countries (uniform or by population or income).

In "concept zero", inequality between countries is addressed by ranking countries according to their total income, with each country given the same weight. This concept is the most appropriate for analysing issues of geopolitics and access to markets. In "concept one", inequality between countries is estimated considering the per capita income of each country, again weighted equally. This can be used to assess the empirical validity of the convergence or divergence postulated by the different growth models. Neither of these two concepts will be used in the analysis presented below. In "concept two", inequality among all individuals in the world is considered by assuming that their income is the per capita income of their country. This concept is known as inequality between countries and can be obtained in the same way as "concept one", but in this case weighting countries by population size. In "concept three", which is adopted in the analysis discussed below, inequality between individuals is measured by considering the per capita income of the household to which they belong. This measure is the global analogue of the distribution generally used to measure inequality within countries; in other words, it is equivalent to assuming that there are no borders. In the remainder of this section, references to global inequality refer to this latter indicator.

Several recent articles have analysed this concept of global inequality and its evolution; and three of them share methodological criteria that make comparison possible. Unfortunately, as they are based on data from household surveys, the oldest calculations only go back as far as the 1980s. These are the studies by Lakner and Milanovic (2016), Niño-Zarazúa, Roope and Tarp (2014), and Anand and Segal (2015), whose systematization provides an updated panorama of the state of the art in the subject. ${ }^{1}$ These studies use data from each country's household surveys to estimate its income distribution profile and average income. Income distribution quantiles (generally ventiles) are considered for each country; average per capita income is attributed to each quantile, and a database is constructed of the quantiles of the different countries of the world. ${ }^{2}$ To make the incomes comparable, they are converted into a common format, using purchasing power parity (PPP) indices. ${ }^{3}$

An initial result that is common to all three studies is that global inequality is very high -comparable to that of the most unequal countries in the world, if not higher. Table 1 shows that the global Gini index varies between 67 and 72.2, depending on the year and the estimate considered. There are no major movements in the indicator during the period considered: the three studies analysed find variations of around 2 points over a period of two decades. These authors note that the differences are small enough to suspect that they are not statistically significant; and what stands out is the stability of the measurement. ${ }^{4}$ An update of Lakner and Milanovic (2016) incorporates data up to 2011 and concludes that the global Gini index has dropped sharply in recent years to reach a level of 64 (Milanovic, 2016).

\footnotetext{
1 Anand and Segal (2008) review previous studies on the subject and also discuss Bourguignon (2015), which is not reviewed here since it makes different methodological choices that do not allow comparison with the other results. In particular, in Bourguignon (2015) the per capita-income data obtained from household surveys is rescaled to coincide on average with the per capita income reported in the national accounts.

2 In the referenced studies, population coverage exceeds $90 \%$ of the world population in the most recent years, but there are major gaps in the earlier period, when household survey data was not generalized in all countries.

3 In all three cases, the data are expressed in 2005 dollars using the World Bank conversion factor.

4 Since surveys from different sources using different sampling methodologies are considered, the standard errors of the global measurement cannot be calculated.
} 
Table 1

Global Gini coefficient

(Percentages)

\begin{tabular}{lccc}
\hline & Lakner and Milanovic (2016) & $\begin{array}{c}\text { Niño-Zarazúa, Roope } \\
\text { and Tarp (2014) }\end{array}$ & Anand and Segal (2015) \\
\hline $1985-1988$ & 69.4 & 70.2 & 72.2 \\
\hline $1993-1995$ & 69.1 & 70.4 & 71.9 \\
\hline 1998 & 68.4 & - & 71.5 \\
\hline $2002-2003$ & 68.7 & - & 71.9 \\
\hline $2005-2008$ & 67 & 68.1 & 70.5 \\
\hline
\end{tabular}

Source: Prepared by the authors, on the basis of C. Lakner and B. Milanovic, "Global income distribution: from the fall of the Berlin Wall to the Great Recession", World Bank Economic Review, vol. 30, No. 2, Washington, D.C., World Bank, 2016; M. Niño-Zarazúa, L. Roope and F. Tarp, "Global interpersonal inequality: trends and measurement", WIDER Working Paper, No. 2014/004, Helsinki, World Institute for Development Economics Research (UNU-WIDER), 2014; and S. Anand and P. Segal, "The global distribution of income", Handbook of Income Distribution, A. Atkinson and F. Bourguignon (eds.), vol. 2, Amsterdam, Elsevier, 2015.

To gain a better understanding of the factors underlying this apparent stability, two components of inequality are distinguished: between countries and within them. A measure of income inequality between countries is calculated by assuming that each person's income is equal to their country's per capita income. The difference between global inequality and this measure of inequality between countries is the component attributed to inequality within countries. ${ }^{5}$ The three studies reviewed agree that inequality is greater between countries than within them. Lakner and Milanovic (2016) note that, if in 2008 the average per capita incomes of the countries were equalized, while maintaining the income distribution within each one, then global inequality would fall by roughly $77 \%$. In contrast, if incomes within the countries were equalized and the differences between them maintained, then global inequality would only fall by $24 \%$.

While inequality within countries became more accentuated in the period analysed, that between countries declined. In other words, the increase in inequality within countries was more than offset by a sharp reduction in differences between them, leading in turn to slight falls in the global inequality indicator. The divergent trends of inequality between and within countries causes important changes in the composition of the global index: for example, Niño-Zarazúa, Roope and Tarp (2014) estimate that the within-countries component of inequality accounted for $20.4 \%$ of the global index in 1985 , but the proportion had almost doubled to $38.8 \%$ by 2005 . These movements mainly reflect developments occurring in China and, to a lesser extent, in India. Both of these countries experienced an increase in inequality and alongside strong growth in average income. Given these countries' large share of the world's total population, their movements make inequality grow within countries globally and reduce inequality between them. The simulation described by these authors shows that, if these countries had grown at the rate they actually did but their income distribution had not changed relative to 1975, global inequality would have fallen $3 \%$ further than it actually did. On the other hand, the authors note that, if the population of China and India had grown at the rate that it did but the income and distribution of 1975 had been maintained, inequality in 2005 would have increased significantly (by 12\%).

\footnotetext{
5 This measure of inequality between countries is a weighted average of inequality within each country. When using the Theil index (GE (1)) as a measure of inequality, this is weighted by each country's share in global income. When the selected inequality indicator is the mean deviation of the logarithmic income (GE (0)), each country is weighted according to its share in total population.
} 
The importance of China and India is also clearly revealed in a graphical analysis of the evolution of the global income distribution (see figure 1). Two major movements stand out: the rightward shift of the distribution in the period considered (which implies income growth) and the change in the shape of the distribution, with the double mode gradually tending to disappear.

Figure 1

Global income distribution, selected years ${ }^{a}$

(Log income density and PPPb dollars at 2005 prices)

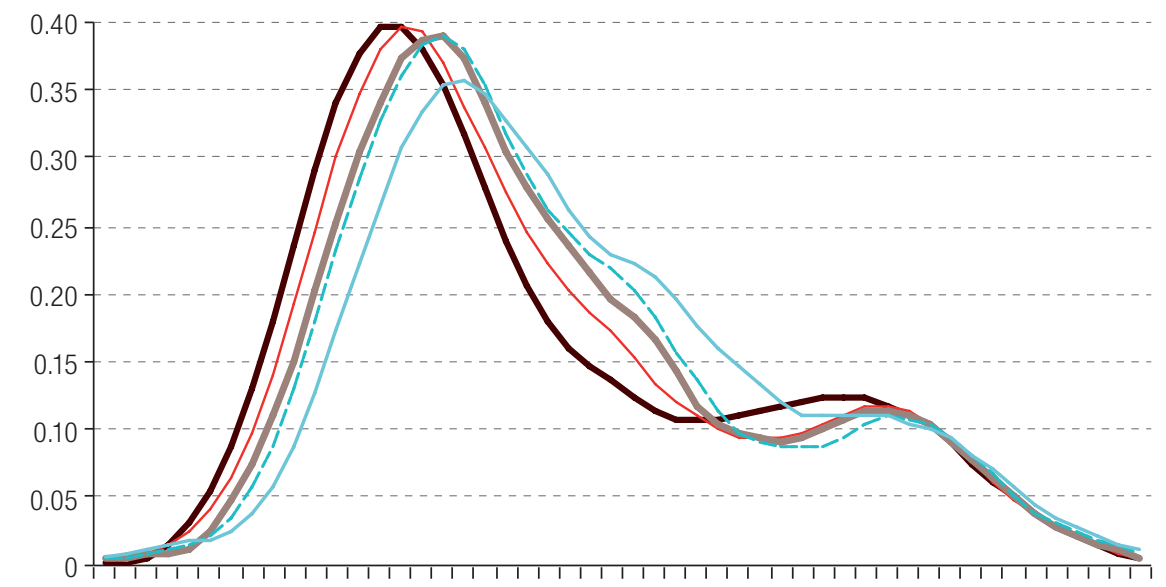

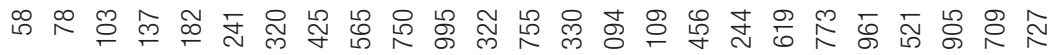

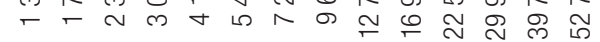

- $1988-1993-1998-.-2003-2008$

Source: Lakner, C. and B. Milanovic, "Global income distribution: from the fall of the Berlin Wall to the Great Recession", World Bank Economic Review, vol. 30, No. 2, Washington, D.C., World Bank, 2016.

a Population-weighted logarithmic scale.

b Purchasing power parity.

Lakner and Milanovic (2016) note that both movements can be explained almost entirely by the changes recorded in China and, to a lesser extent, in India. Both of these countries shift to the right in the distribution (see figure 2), leaving sub-Saharan Africa on the far left.

Figure 2

Global ncome distribution, selected years ${ }^{\mathrm{a}}$

(Log income density and PPPb dollars at 2005 prices)

A. 1988

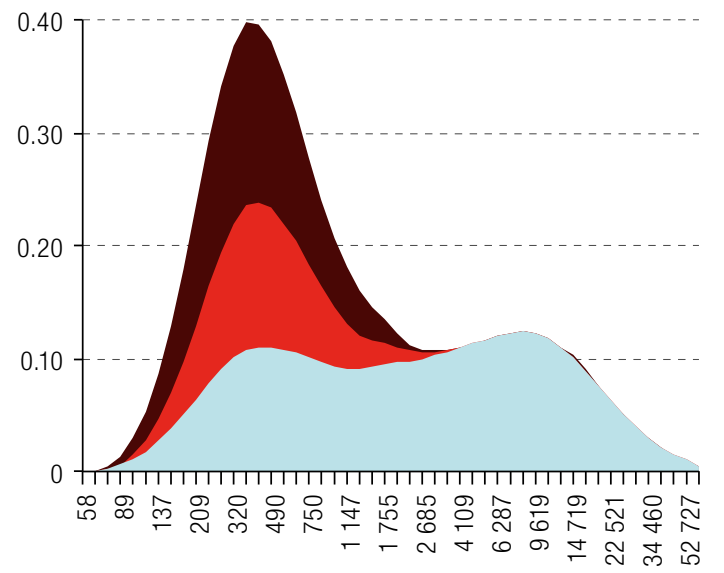

B. 1993

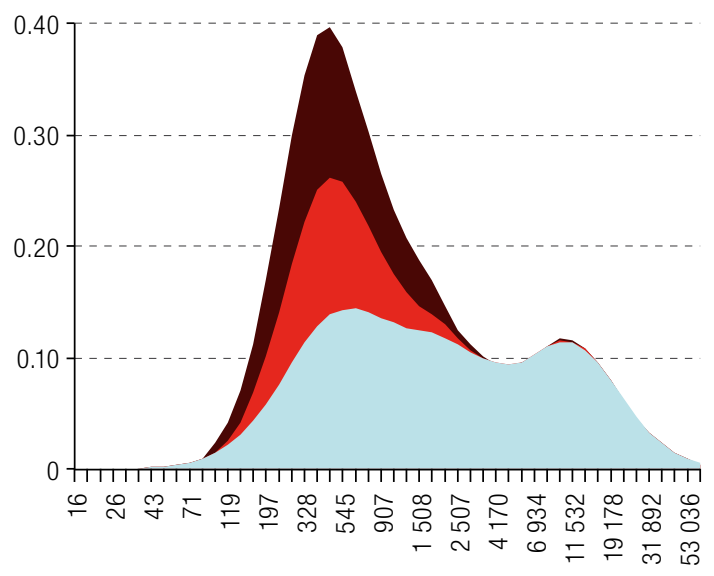

Rest of the world 
Figure 2 (concluded)

C. 1998

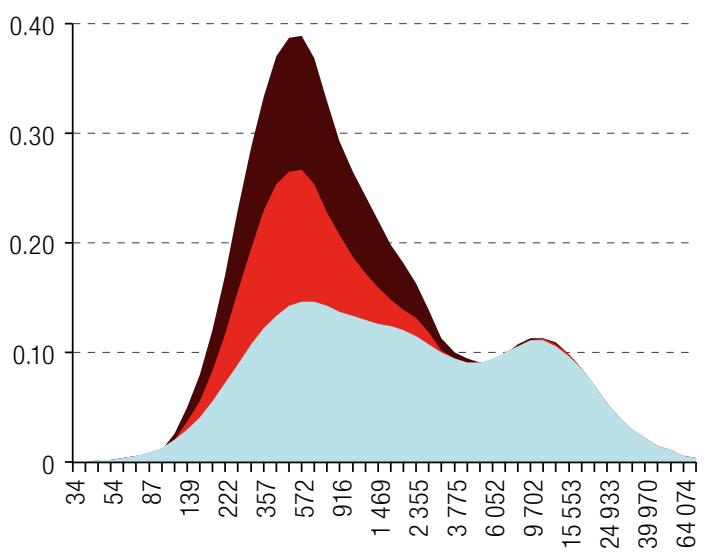

D. 2003

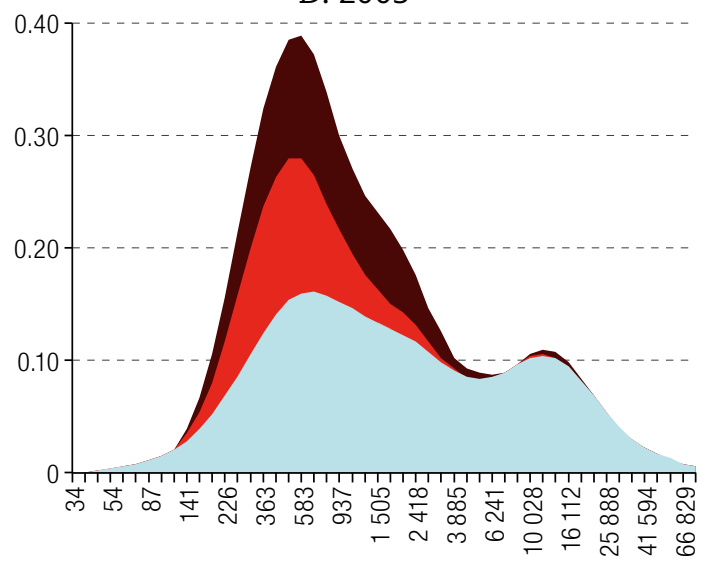

E. 2008

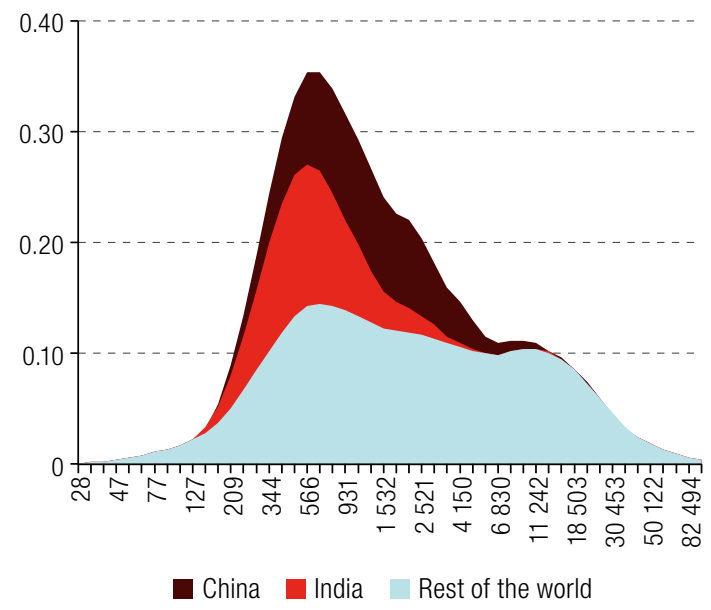

Source: Lakner, C. and B. Milanovic, "Global income distribution: from the fall of the Berlin Wall to the Great Recession", World Bank Economic Review, vol. 30, No. 2, Washington, D.C., World Bank, 2016.

a Logarithmic scale.

b Purchasing power parity.

In short, the studies reviewed show that, in all time periods analysed, global inequality is very high, at levels similar to or above those of the most unequal countries in the world. Between the 1980s and the decade of 2000, the main indicators remain stable or, at best, decrease slightly in the most recent years. Inequality between countries accounts for the majority of global inequality and has fallen moderately; while inequality within countries has increased greatly. These movements are mainly explained by trends in China and India, where economic growth in the period went hand-in-hand with a sharp increase in domestic inequality, while incomes approached middle-income country levels.

\section{Inequality in developed and developing countries}

Analysing inequality at the country level is a complex task, since context and evolution differ. The literature usually considers developed and developing countries separately, since the determinants of inequality and its evolution seem to differ between the two groups.

In recent studies that include data on inequality in developed countries, the indicators vary widely, ranging from a Gini index of 0.25 in Denmark, Iceland, Norway and Slovenia, to 0.41 in Turkey and 0.39 in the 
United States, according to information from the Organization for Economic Cooperation and Development (OECD) (see figure 3). The Nordic countries (Sweden, Norway, Denmark and Finland) are among those with the lowest levels of inequality, along with the Benelux nations (Belgium, Holland and Luxembourg) and some Eastern European countries. Turkey, the United States, Israel and Russia are at the opposite extreme.

Figure 3

Developed countries: Gini index of equivalized household disposable income, around 2011

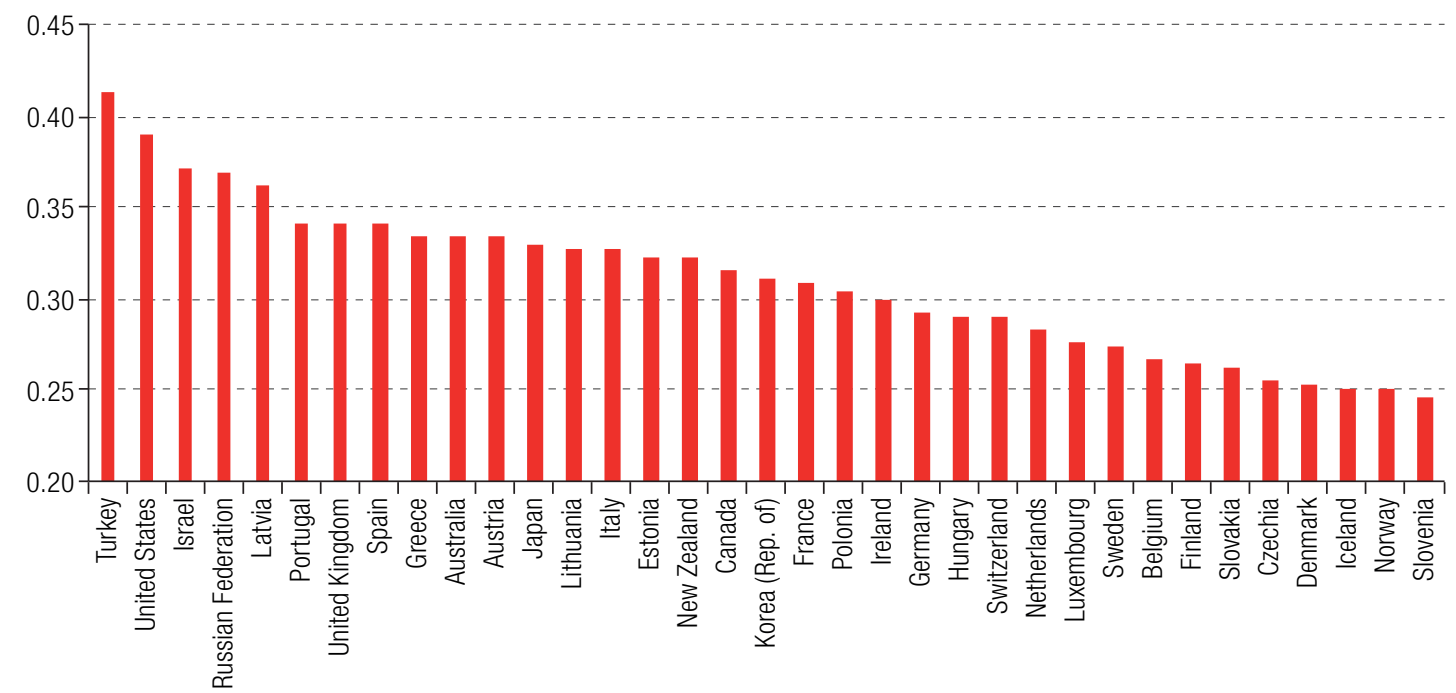

Source: Organization for Economic Cooperation and Development (OECD), OECD Income Distribution Database.

The trend between 1975 and 2010 shows inequality increasing in practically all developed countries for which information is available (see figure 4). In some cases (the United States, the United Kingdom and the Netherlands), inequality grew strongly in the 1980s; while in others (Canada, the Nordic countries and Germany) this happened in the 1990s. Even in France, which achieved a sharp drop in its Gini coefficient, the indicator rose in the decade of 2000 (Morel li, Smeeding and Thompson, 2015). Owing to these movements, inequality among high-income countries displays less dispersion than in the 1980s; but the country inequality ranking remains basically unchanged during the period.

Figure 4

High-income countries: trend of the Gini coefficient of household disposable income, 1975-2010

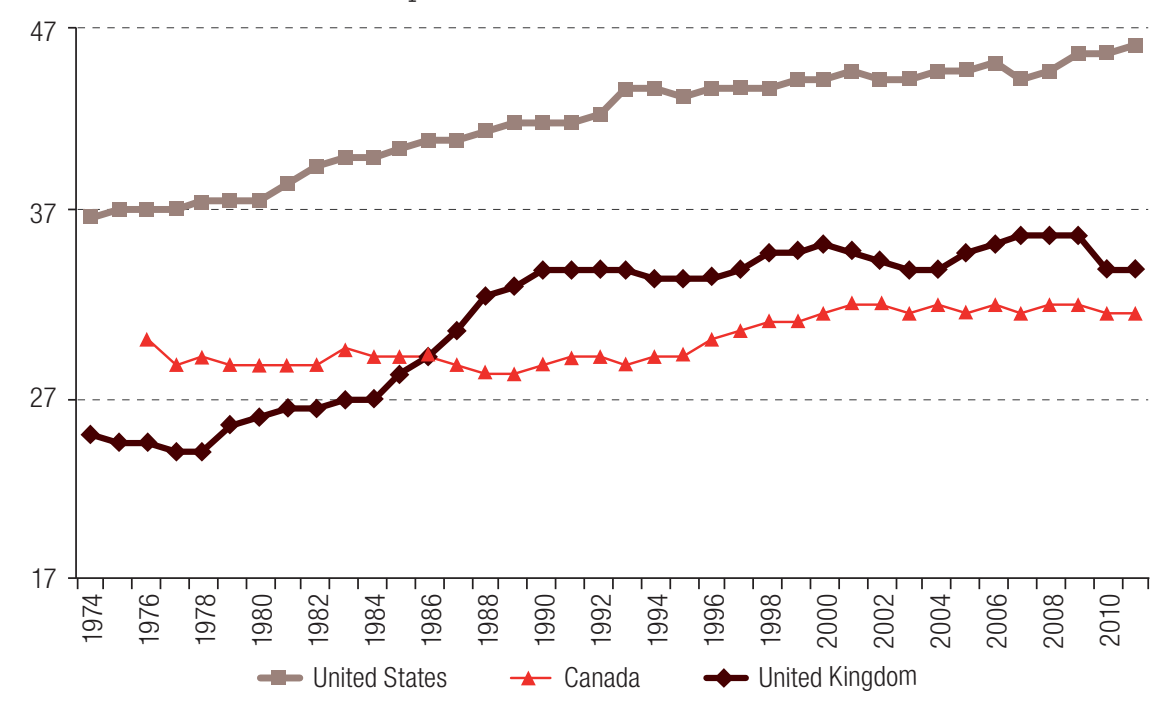


Figure 4 (concluded)

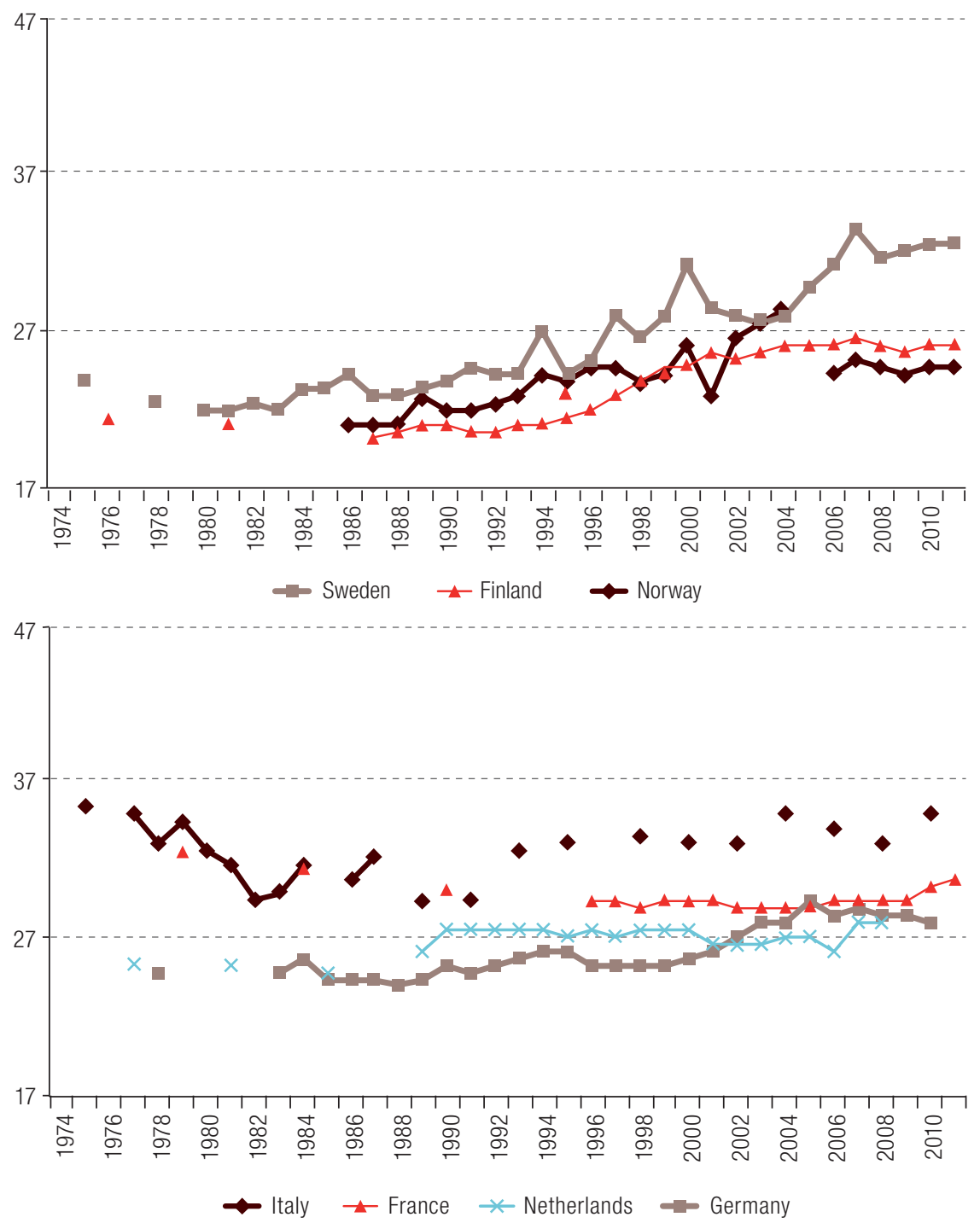

Source: Prepared by the authors, on the basis of A. B. Atkinson and S. Morelli, "Chartbook of economic inequality", ECINEQ Working Paper Series, No. 2014-324, Society for the Study of Economic Inequality (ECINEQ), 2014.

Although household surveys clearly provide up-to-date and comparable data that make it possible to construct indicators of inequality in the different countries of the world, these surveys also have major shortcomings in terms of capturing high incomes (Atkinson, Piketty and Sáez, 2011), in developed and developing countries alike. In the former, Morelli, Smeeding and Thompson (2015) show how, beyond the methodological problems involved in comparing data from tax records, the ranking of countries by inequality levels does not change much when the income appropriated by the top $1 \%$ is used as an inequality indicator. ${ }^{6}$ These authors also draw attention to the rising trend of this indicator in developed countries, and to the fact that the 2008 financial crisis did not cause a structural break in this trend. In relation to the English-speaking countries, Piketty and Sáez (2013) find that the increase in inequality would be even more pronounced, if the incomes of the richest were properly measured.

\footnotetext{
${ }^{6}$ Ruiz and Woloszko (2016) obtain similar results by applying a statistical adjustment to household survey data in developed countries.
} 
The reasons for this growth in inequality in developed countries remains a matter of debate, and several explanations have been put forward. Firstly, the process of technological innovation may have fuelled demand for skilled workers and thus increased the wage differential in their favour. Trade and financial liberalization, in addition to globalization, could have had a similar effect in pushing up skilled wages in developed economies and thus aggravating inequality. In practice, it is very hard to separate the two effects - globalization and trade liberalization - since technological progress, for example, allows for the fragmentation of productive activities and production abroad, which can be interpreted as an effect of trade specialization (OECD, 2011). More recently, and especially since the global financial crisis of 2008, emphasis has been placed on the growing importance of the financial sector in the economies. This is consistent with Piketty's widely publicized claim (2014) that the rate of return on capital has been higher than the long-run economic growth rate, and that this return has been concentrated in very few hands, thereby fuelling a large increase in economic inequality.

Inequality levels display greater dispersion in developing countries than in developed ones, with the range of Gini coefficients spanning nearly 40 points, from 25.6 in Ukraine to 63.1 in South Africa (Alvaredo and Gasparini, 2015). Figure 5 shows the Gini indices of 122 developing countries grouped according to their respective regions. ${ }^{7}$ While sub-Saharan Africa is the region containing countries with the highest levels of inequality, it also displays the greatest dispersion. Its (unweighted) average inequality is the highest in the world, although the median of Latin American countries is higher. Moreover, nearly all countries in the world with very high levels of inequality (Gini coefficients of over 50) are located in sub-Saharan Africa; but that region also has a similar share of countries with medium or high levels of inequality. In contrast, nearly all Latin American countries have high levels of inequality. Eastern Europe and Central Asia are the only regions containing countries with low levels of inequality (below 30 points). In the other three regions of the world, most countries are in the medium-inequality range.

Figure 5

Developing countries: Gini coefficient of per capita household consumption, around 2010

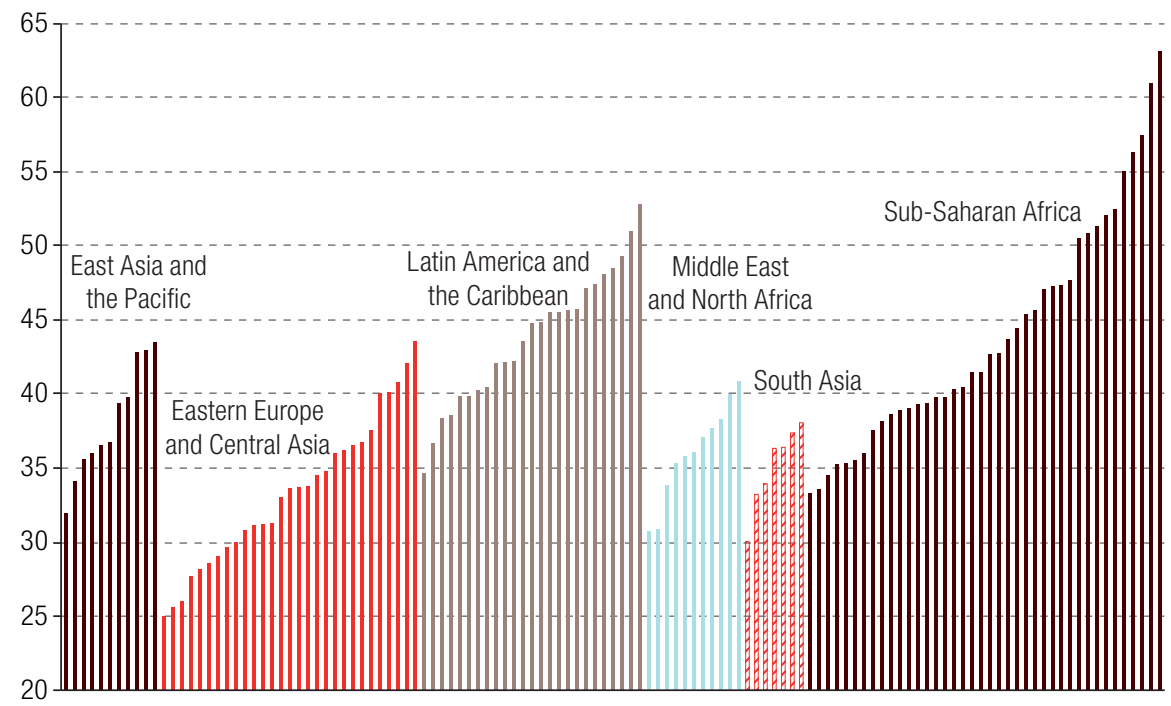

Source:F. Alvaredo and L. Gasparini, "Recent trends in inequality and poverty in developing countries", Handbook of Income Distribution, A. Atkinson and F. Bourguignon (eds.), vol. 2, Amsterdam, Elsevier, 2015.

\footnotetext{
7 These figures are obtained from PovcalNet, which reports the distribution of per capita consumption, except for Latin America and some Caribbean countries where the distribution of per capita income is shown. For the data to be comparable, Alvaredo and Gasparini (2015) adjust the records of this region based on the Gini index of consumption or income taken from seven countries for which information is available. In these seven countries, the average Gini index of consumption or income is 0.861 .
} 
The differences between countries are much greater than the changes they experience through time. Alvaredo and Gasparini (2015) analyse a panel of developing countries in the period spanning 1981 to 2010 and find that $88.5 \%$ of the variance in the panel is due to differences between countries. These authors also note that the country ranking has remained virtually unchanged, even though the developing world has undergone major political, economic and social changes in the last four decades. This suggests that there are certain underlying factors that greatly affect the level of inequality in a country, and that these have not changed over time. Figure 6 shows movements in the average Gini coefficient by region between 1990 and 2010, calculated on the basis of per capita consumption cited in the aforementioned article.

Figure 6

Developing countries (six regions): Gini coefficient of per capita consumption, 1990-2010a

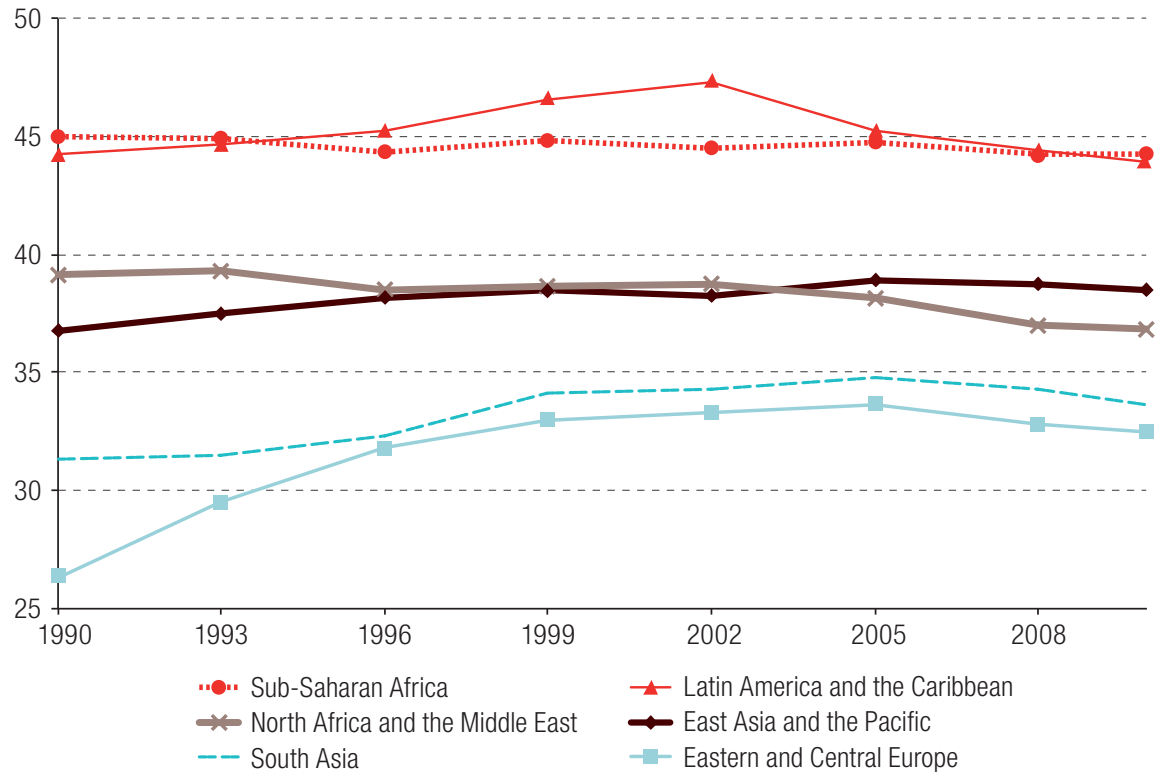

Source: F. Alvaredo and L. Gasparini, "Recent trends in inequality and poverty in developing countries", Handbook of Income Distribution, A. Atkinson and F. Bourguignon (eds.), vol. 2, Amsterdam, Elsevier, 2015.

a Unweighted average for each region.

Whereas the Gini index in Latin America rose in the 1990s but dropped back in the decade of 2000, the index for sub-Saharan Africa remained practically unchanged. In contrast, inequality increased vigorously in Asian and Eastern European countries. In Asia, the greatest increase in occurred in China, where income growth was so great that it impacted on the global distribution, as discussed in the previous section. This phenomenon is now analysed further, while the trend of inequality in Latin America is considered in greater depth in section $\mathrm{V}$.

\section{Deeper analysis of selected realities: inequality in China}

Household income growth in China has been so rapid that it has caused a rightward shift in the global income distribution and a change in its shape, as discussed in section I. The expansion of Chinese production and job growth fuelled a significant increase in workers' pay and household income. This meant, firstly, a very substantial reduction in poverty levels: according to World Bank estimates, the 
proportion of people with per capita incomes of less than US\$ 2 per day (in purchasing power parity terms at 2005 prices) fell from $84 \%$ in 1987 to just under 19\% in 2011. Relative to a poverty line of US\$ 1.25 , the poverty rate fell from $54 \%$ to $6 \%$ in the same period.

On the other hand, there was a sustained increase in inequality, since the gains generated by this rapid economic growth were not equally shared among the different households, social groups or regions of the country. The last available figure for the Gini coefficient (2012) is 54, which implies a rise of 25 points since 1982 and nearly 15 points relative to the values of 2000 (see figure 7). In other words, along with the remarkable growth of the economy and the reduction of poverty, inequality has skyrocketed.

Figure 7

China: economic growth and inequality, 1981-2014

(Percentages and Gini coefficients)

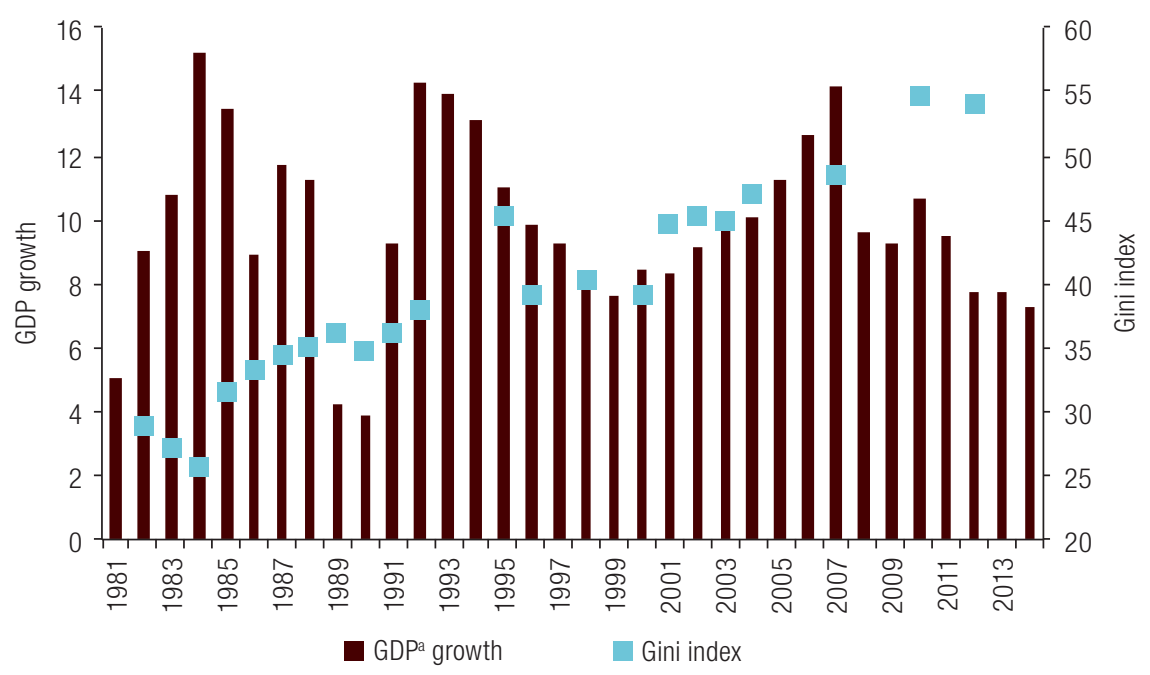

Source: International Monetary Fund (IMF), World Economic Outlook Database and World Institute for Development Economics Research (UNU-WIDER), World Income Inequality Database.

a Gross domestic product.

Numerous studies have highlighted the vertiginous rise of income inequality since the 1978 economic reform (Meng, Shen and Sue, 2013; Xie and Zhou, 2014). This reform encouraged the rapid urbanization and industrialization of certain "special economic zones", where the engine of economic growth of the last 25 years was concentrated. Foreign capital flowed into these areas, spawning industrial enterprises and greatly expanding demand for labour. This was accompanied by housing subsidy programmes in urban areas, in response to a strong flow of immigration from rural zones. Based on this process, today there is a significant difference between wages received in the urban coastal zone and pay levels in rural areas (Tao Yang and Zhou, 1999; Sicular and others, 2007). Given that municipalities (counties) are responsible for collecting a large proportion of tax revenue and providing services such as education, health and even pensions, there are major differences in public service quality between areas with different income levels (Dollar, 2007).

In addition to regional inequality, education premia have increased considerably and are currently a powerful differentiator between the wages of urban workers in China (Xie and Zhou, 2014). Between 1988 and 1995, education premia almost doubled (Hauser and Xie, 2005) and the upward trend continued in later years (Jansen and Wu, 2012). Previously, wage levels were very similar between the different professions and technical capacities. The reform process, in conjunction with greater market participation and the retreat of public-sector activity and employment in recent years, has widened schooling-based wage differentials. As of 1999, the Chinese government introduced a policy to expand 
tertiary education, thanks to which the proportion of urban population with a university degree rose from less than $10 \%$ in 2003 to over $20 \%$ in 2010 . This change, in conjunction with other variants in schooling levels among the Chinese labour force between 1996 and 2010, seems to have fuelled greater inequality (Zhou, 2014). While the Chinese population has seen its absolute level of income rise along with a rapid increase in inequality, declining levels of happiness or satisfaction with life were detected in various jobs between 1990 and late 2000 (Bartolini and Sarracino, 2014; Brockmann and others, 2009). This has been associated with a population segment that feels relatively disadvantaged and whose expectations are not being fulfilled, even though its situation has improved in absolute terms.

\section{Deeper analysis of selected realities: inequality in Latin America}

This section makes a detailed analysis of the trend of inequality in Latin America over the last decade, between 2002 and 2014. Just as global inequality was examined above, the analysis starts by using the global inequality methodology, considering the region as a whole, and then focuses on national realities.

\section{Regional inequality}

The application of a methodology similar to that used in global studies of inequality, but considering Latin American countries only, makes it possible to gauge income inequality among the inhabitants of the region as a whole, and see how that inequality has evolved. Since this calculation involves fewer countries, it is possible to combine individual data from all of the household surveys conducted in the region, instead of combining ventiles as is done in global inequality studies. A regional income vector is obtained, and its distribution and recent modifications are analysed to ascertain whether the distributive changes occurring within the countries of the region in the last decade have been accompanied by improvements in the distribution of income among Latin Americans, or if the gaps have widened. Then, the results of an exercise of this type are used to update the analysis of Amarante, Galván and Mancero (2016), considering 16 the region's countries at three points in time: around 2002, 2009 and $2014 .{ }^{8}$ In addition, a number of simulation exercises are presented. ${ }^{9}$

Two alternative vectors are used to obtain income figures that are comparable between countries. The first of these is PPP-adjusted per capita household income (World Bank, 2015). ${ }^{10}{ }^{11}$ As an alternative way of equalizing the purchasing power of households and analysing the robustness of the results, the poverty lines calculated by the Economic Commission for Latin America and the Caribbean (ECLAC) to estimate poverty at the regional level are used as price deflators. As these poverty lines represent the cost of acquiring a basic basket of food products and goods that satisfy other basic needs, they

\footnotetext{
8 A similar analysis can be reviewed in Cord and others (2016).

9 Table A1.1 of the annex provides a breakdown of the surveys and the years used.

10 Incomes were updated to 2011 according to the variation recorded in each country's general consumer price index (CPI), in order to apply the PPP factors estimated for that year. In the case of Argentina, the simple average of the price indices of five provinces has been used as a deflator since 2007. As the reliability of the estimates made under the 2011 PPP is subject to debate, all estimates are made using the 2005 PPP conversion factors. The results, which are very similar, can be requested from the authors.

${ }^{11}$ Both income vectors (adjusted for PPP and deflated by poverty lines) use household income corrected for non-response to the surveys and adjusted to the national accounts figures. This is the income measurement that ECLAC used to calculate poverty up to 2016 (see ECLAC, 2014b). As from Social Panorama of Latin America 2016 (ECLAC, 2016), a new series of household income has been presented in which the various items included, and the imputation of non-response are revised from the conceptual and operational standpoints. The figures are also not aligned to the national accounts.
} 
can be interpreted as reflecting the differences in the cost of achieving a similar level of wellbeing between countries.

A glance at the global PPP-adjusted income distribution for Latin America reveals its sharp shift to the right between 2002 and 2009, reflecting the growth of household income (see figure 8). This movement is repeated in 2014, albeit to a lesser extent. Comparing one period with the other also shows that the distribution has become less dispersed.

Figure 8

Latin America, income distribution 2002, 2009 and $2014^{\mathrm{a}}$

(Log income density and $\mathrm{PPP}^{b}$ dollars at 2011 prices)

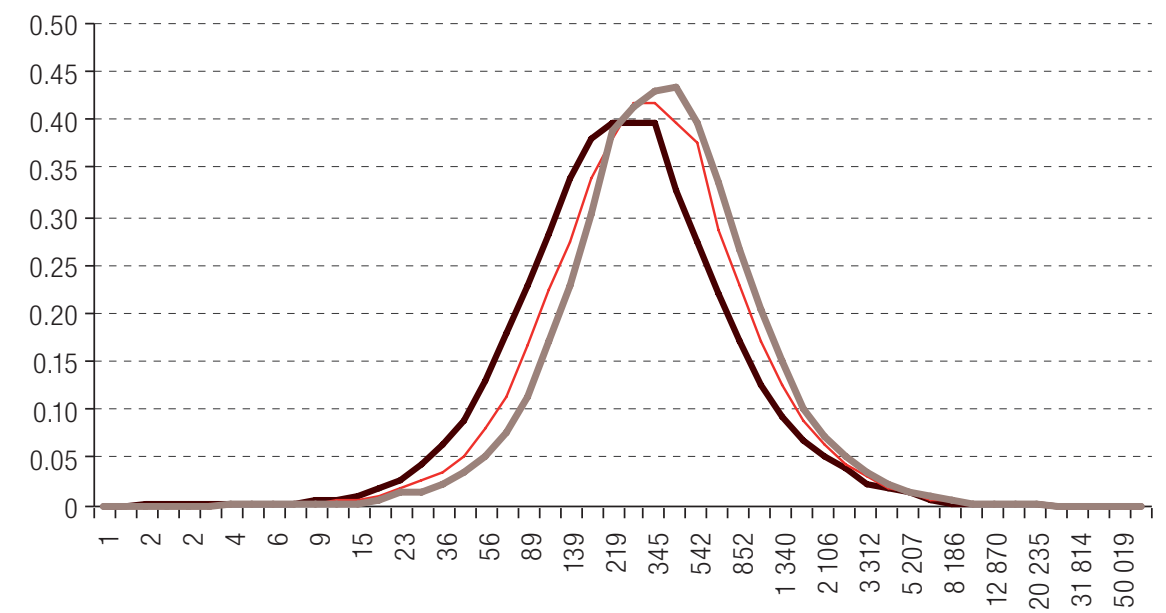

$-2002-2009-2014$

Source: Prepared by the authors, on the basis of household surveys.

a Population-weighted logarithmic scale.

b Purchasing power parity.

The average per capita income of the inhabitants of Latin America grew by $30.5 \%$ between 2002 and 2014 in purchasing power parity terms, and by 39.7\% if expressed relative to the poverty line. In that period, income grew in all percentiles of the distribution, although not uniformly: the lower percentiles achieved higher growth, as can be seen from the changes by decile and percentile (see figure 9). Both in terms of PPP-adjusted income, and in terms of the poverty line, the growth declines as the income level rises. According to Ravallion and Chen (2003), the growth incidence curve shows that growth has been pro-poor. This is particularly clear in the case of PPP-adjusted income, which reports stronger growth than income adjusted by the poverty line among households in the lower half of the distribution. The greater growth of income among individuals in the lower part of the regional distribution is therefore an initial indication of less global inequality in the region.

Unlike the global pattern, indicators of inequality in Latin America do not differ significantly from subregional or national observations, which suggests a certain homogeneity in the region, even though the level of the indicator is high relative to other regions. This shows that the differences between the inhabitants of Latin America are broadly similar to those between the inhabitants of each country. In terms of trend, the three indicators considered (Gini, Theil and the 90/10 ratio) show an improvement between 2002 and 2014, whether measured in purchasing power parity terms or relative to the poverty line (see table 2). Nonetheless, in most indicators, the bulk of the improvement occurs between 2002 and 2009, while in recent years the pace of reduction of inequality has slowed substantially, especially when analysing income relative to the poverty line. 
Figure 9

Latin America: variation in real incomes, 2002-2014a

(Percentages)

A. By percentiles of the regional distribution

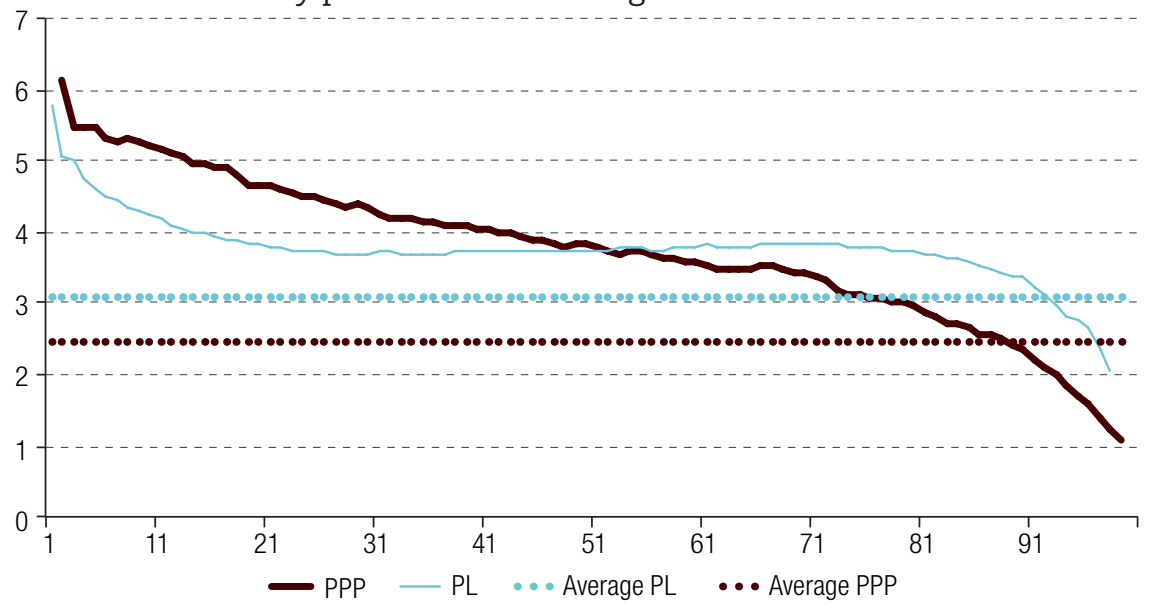

B. By deciles of the regional distribution

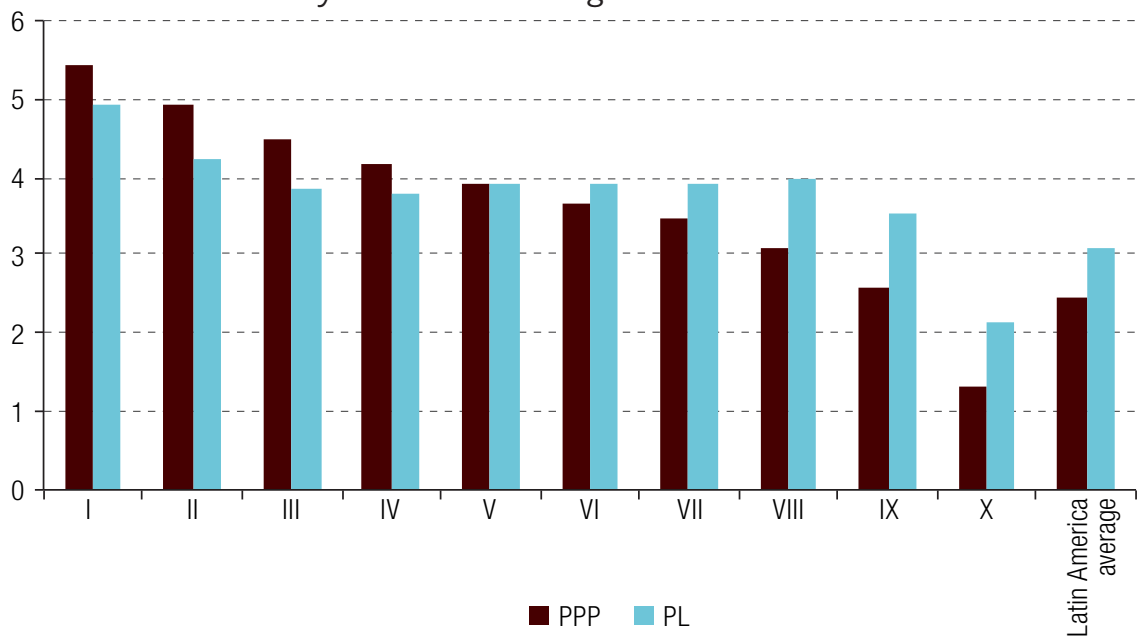

Source: Prepared by the authors, on the basis of household surveys.

Note: PPP means purchasing power parity and PL means poverty line.

Annual equivalent variation.

Table 2

Latin America: global inequality indices, 2002, 2009 and 2014

(Percentage points and percentages)

\begin{tabular}{|c|c|c|c|c|c|c|}
\hline & 2002 & 2009 & 2014 & $\begin{array}{c}\text { Annual equivalent } \\
\text { variation 2002-2014 }\end{array}$ & $\begin{array}{c}\text { Annual equivalent } \\
\text { variation 2002-2009 }\end{array}$ & $\begin{array}{c}\text { Annual equivalent } \\
\text { variation 2009-2014 }\end{array}$ \\
\hline \multicolumn{7}{|l|}{ PPP income ${ }^{a}$} \\
\hline Gini coefficient & 0.588 & 0.553 & 0.532 & -0.8 & -0.9 & -0.8 \\
\hline Theil index & 0.767 & 0.653 & 0.595 & -2.1 & -2.3 & -1.8 \\
\hline $90 / 10$ ratio & 14.5 & 12.6 & 10.9 & -2.4 & -2.0 & -2.9 \\
\hline \multicolumn{7}{|l|}{ PL incomeb } \\
\hline Gini coefficient & 0.580 & 0.552 & 0.551 & -0.4 & -0.7 & 0.0 \\
\hline Theil index & 0.772 & 0.664 & 0.648 & -1.4 & -2.1 & -0.5 \\
\hline 90/10 ratio & 12.3 & 11.4 & 11.3 & -0.7 & -1.1 & -0.1 \\
\hline
\end{tabular}

Source: Prepared by the authors, on the basis of household surveys.

a Purchasing power parity.

b Poverty line. 
If income inequality among the region's inhabitants is broken down into inequality between and within countries (based on the Theil index), it can be seen that most (nearly 90\%) of overall regional inequality originates within the countries (see table 3). This result differs from the global decompositions analysed above, which indicate that between $60 \%$ and $85 \%$ of global inequality worldwide (depending on the measures and years considered) stems from differences between the countries' average incomes, and that this inequality is decreasing. Restricting the analysis to Latin America results in greater homogeneity between countries, as would be expected by reducing the number of countries included in the calculation. Moreover, inequality within countries determines regional inequality almost entirely. These results indicate that the countries' internal dynamics, linked to their social, institutional and political realities, is more relevant for the consideration of regional inequality than dynamics between countries (such as those linked to migration or trade). These results are similar to those found by Amarante, Galván and Mancero (2016) for the region. Nonetheless, each country's contribution to global inequality depends mainly on its share in total household income in the region, hence the importance of Brazil and Mexico, which have a very heavy weight in the decomposition (see table A1.2 of the annex).

Table 3

Latin America: decomposition of the Theil index by country, 2002, 2009 y 2014

(Theil index points and percentages)

\begin{tabular}{|c|c|c|c|c|c|c|}
\hline & \multicolumn{3}{|c|}{ Theil decomposition } & \multicolumn{3}{|c|}{ Weight of the components } \\
\hline & 2002 & 2009 & 2014 & 2002 & 2009 & 2014 \\
\hline \multicolumn{7}{|l|}{ PPP income ${ }^{a}$} \\
\hline Within countries & 73.7 & 61.0 & 55.1 & 96 & 93 & 93 \\
\hline Between countries & 3.0 & 4.4 & 4.4 & 4 & 7 & 7 \\
\hline Theil & 76.7 & 65.3 & 59.5 & 100 & 100 & 100 \\
\hline \multicolumn{7}{|l|}{ PL income ${ }^{b}$} \\
\hline Within countries & 73.1 & 66.4 & 54.9 & 95 & 92 & 85 \\
\hline Between countries & 4.1 & 5.5 & 9.9 & 5 & 8 & 15 \\
\hline Theil & 77.2 & 60.9 & 64.8 & 100 & 100 & 100 \\
\hline
\end{tabular}

Source: Prepared by the authors, on the basis of household surveys.

a Purchasing power parity.

b Poverty line.

Moreover, the reduction in the region's global inequality during the period is mainly explained by the decrease in inequality within the countries. Here again, the processes of distributive improvement that have occurred in Brazil and Mexico are very important. The importance of the between-country component of inequality (which reflects differences between per capita incomes) has increased. Inequality between countries explains a smaller, although growing, part of global inequality in the region. These results show that living conditions among Latin American people are relatively more uniform today than they were a decade ago, although the differences in country per capita incomes are larger. The decrease in global inequality in the region, together with the absolute prevalence of intra-country inequality and its deconcentrating effect, are similar to, although more accentuated than, the findings reported by Gasparini and Gluzmann (2012) relative to 1992-2006 and those reported by Amarante, Galván and Mancero (2016).

Two simulation exercises are performed (see table 4). The first consists in calculating a hypothetical Latin American income distribution for 2014, as if only its structure had changed, but average income had not risen relative to 2002 (distribution effect). The second calculates a hypothetical distribution for 2014 assuming only the average income of the countries had changed, but not the structure of the distribution relative to 2002 (growth effect). If income had not grown between 2002 and 2014, but its structure had changed, the Gini index would have fallen even more steeply (dropping to 0.524 instead of 0.532 in 2014). In contrast, if income had merely increased, but its structure had not changed, inequality would have increased, and the Gini index would have been 0.595 in 2014. This indicates 
that the two movements observed in the period have opposite effects on inequality: average income growth has been unequal, but the change in the structure of income has more than offset this effect. ${ }^{12}$

Table 4

Latin America: simulations of income inequality per capita, 2014

(PPP dollars ${ }^{a}$ at 2011 prices and indicator points)

\begin{tabular}{lcccc}
\hline & 2002 & 2014 & Distribution effect & Growth effect \\
\hline Average income & 477 & 622 & 475 & 623 \\
\hline Gini index & 0.588 & 0.532 & 0.524 & 0.595 \\
\hline Theil index & 0.767 & 0.595 & 0.581 & 0.752 \\
\hline 90/10 ratio & 14.5 & 10.9 & 10.6 & 14.3 \\
\hline
\end{tabular}

Source: Prepared by the authors, on the basis of household surveys.

a Purchasing power parity.

In summary, as reported in Amarante, Galván and Mancero (2016) for 2002-2012, the regional inequality indicators dropped sharply in 2002-2014, which indicates that the relative differences across the population regionwide are smaller than a decade ago. The reduction in inequality within countries is what basically explains the drop in global inequality across the region; and it is mainly the change in the structure of income (the distribution effect) that explains this.

\section{Inequality at the national level}

Income inequality, measured through the Gini index, has declined in nearly all Latin American countries analysed since 2002 (see figure 10). The two exceptions are Costa Rica and the Dominican Republic where the index rises (in the latter case, only in 2009). ${ }^{13}$ The best relative achievements between 2002 and 2014 occur in the Plurinational State of Bolivia, the Bolivarian Republic of Venezuela, Argentina, Paraguay and Uruguay, with reductions of more than $4 \%$ per year. ${ }^{14}$

Figure 10

Latin America (16 countries): Gini index, 2002, 2009 and 2014

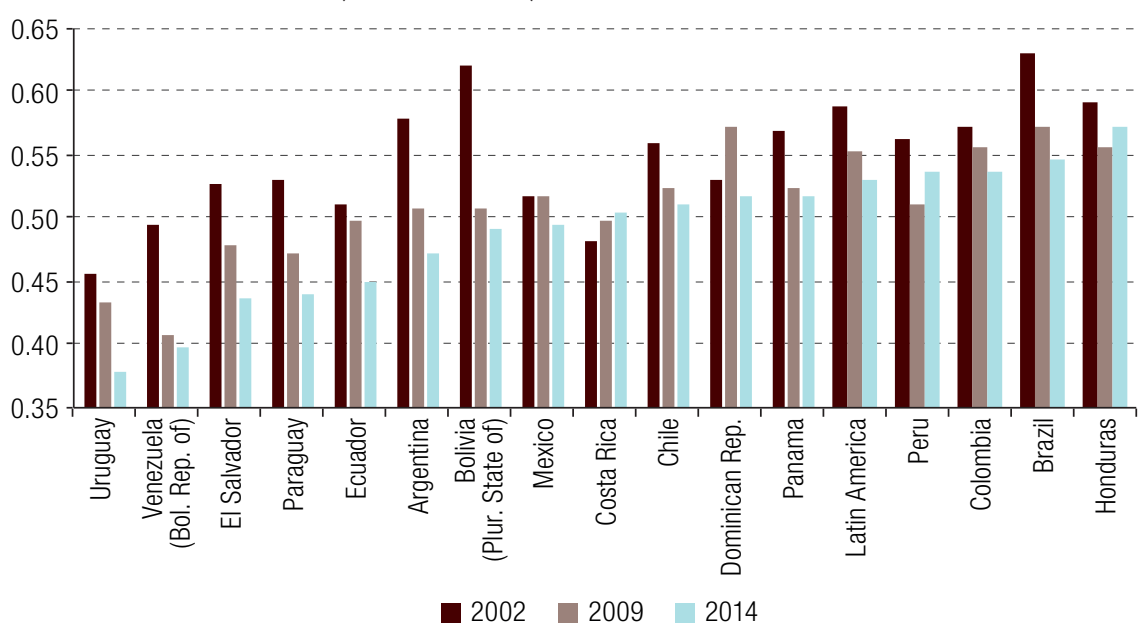

Source: Prepared by the authors, on the basis of household surveys.

\footnotetext{
12 If the decompositions are based on the end-year of the period instead of the initial one, the results are almost identical.

13 In the case of Costa Rica, methodological changes were made to the household survey in 2010 that cast doubt on comparability of the series.

14 The reduction in income inequality occurs a little later, starting in 2007.
} 
Different inequality trends across countries change the income-inequality ranking. For example, Argentina and the Plurinational State of Bolivia were among the region's five most unequal countries in 2002 (along with Brazil, Honduras and Colombia), whereas in 2014 they are located in the upper middle range of the table, ranked 6 th and 7 th, respectively.

Income inequality in Latin America has trended up since the 1980s, with a different dynamic in each country, but with the persistence and high levels that have historically been characteristic of the region. The decline that began in most countries in 2002 largely reflects labour market developments, where the dispersion of labour income narrowed considerably. In a context in which average income varied widely, incomes in the lowest part of the distribution - pertaining to low-skilled workers - grew by more, which reduced the skill premium. This could be due to an increase in the supply of skilled workers, an increase in the demand for less skilled workers or a combination of the two. Nonetheless, beyond the general patterns, national experiences are dissimilar, and several factors, operating with different intensities, may have contributed to the aforementioned reduction. Thorough discussion on this can be found in ECLAC (2014a), Gasparini and others (2012), and Cornia (2014), among other sources. In general, macroeconomic stability and external conditions have favoured the region in the period analysed. More specifically, labour market institutions, such as the minimum wage and collective bargaining arrangements, have contributed significantly in the Southern Cone economies (see, for example, Maurizio and Vázquez, 2016). In the Central American economies, non-labour income sources, particularly remittances, have had an equalizing impact in some cases (Acosta and others, 2008). More generally, non-contributory transfers to households with children and non-contributory pensions helped reduce inequality in the previous decade.

Given the heterogeneity prevailing in Latin America, it is useful to make a detailed analysis of movements in its constituent subregions, of which five are considered: Central America, the Andean Region, the Southern Cone, Mexico and Brazil. The two latter countries are considered separately owing to their preponderance in the region, in terms both of population and income. As noted in section I, the region's Gini index shows that Latin American incomes are becoming less unequal, although the process seemed to be faltering at the end of the period. The regional movements basically reflect what happened in South America, since patterns in both Mexico and Central America are different. On this point, the relative size of Brazil in the region, in terms of both population and income (37\% and $45 \%$, respectively, in 2014), means that movements occurring in that country have a significant impact on the aggregate indicator for Latin America.

While Central America was the most unequal subregion in 2014, Brazil was the least equal in 2002 (see figure 11). The meagre improvement in the Central American indicators, compared to a robust reduction in inequality elsewhere, pushes that subregion into last place. At the other extreme, Mexico is the least unequal part of Latin America, closely followed by the Southern Cone and the Andean Region. Apart from the fall in inequality in the region as a whole, its subregions are converging in terms of inequality.

The variation in income by percentiles displays differential patterns across subperiods and subregions, as shown in figure 12. In one group, the Andean Region, Brazil and the Southern Cone exhibit rapid income growth in all percentiles and a negative gradient, which benefits the poorest households and fosters a reduction in inequality. The second group contains Mexico and Central America, with a lower growth rate that slightly favours to the poor in the case of Mexico but has no distributive effects in Central America (the respective curve is almost horizontal). The Andean Region displays the most uniform movements across subperiods, although initially at a higher level. Average income grows strongly in the lower-income sectors, especially in the first decile. Between the first decile and the last ventil, growth is relatively uniform and significantly lower in the wealthier segments. In Brazil, growth is strong in the low- and middle-income brackets in both subperiods, although in 2002-2009, income growth 
is lower in the last ventil. The Southern Cone records the strongest growth of all subregions, although with a less equal profile than elsewhere. Lastly, Mexico is the only subregion in which income declined in both subperiods, although by more in the second. Nonetheless, among the poorest segments, the second subperiod is more fruitful: while in 2002-2009, average income growth among the poorest is below average, between 2009 and 2014 it is considerably higher, resulting in above-average growth for the whole period.

Figure 11

Latin America (16 countries) a and subregions: Gini index of per capita income, 2002, 2009 and $2014^{\mathrm{b}}$

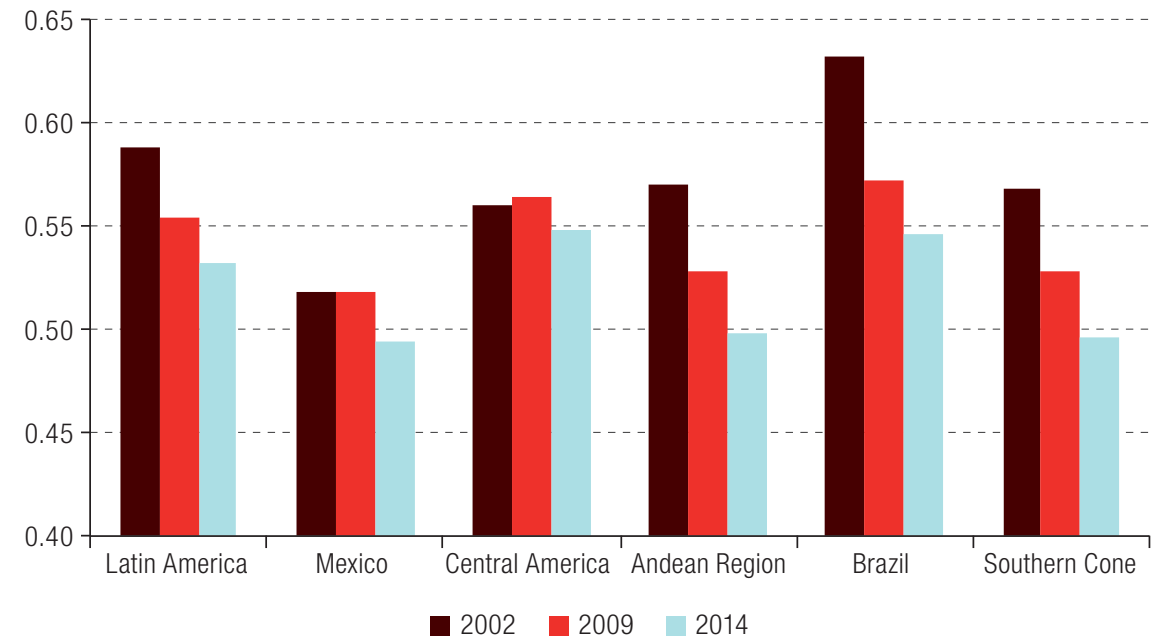

Source: Prepared by the authors, on the basis of household surveys.

a Argentina, Bolivia (Plurinational State of), Brazil, Chile, Colombia, Costa Rica, Dominican Republic, Ecuador, El Salvador, Honduras, Mexico, Panama, Paraguay, Peru, Uruguay and Venezuela (Bolivarian Republic of).

b In purchasing-power-parity (PPP) terms at 2011 prices.

Figure 12

Latin America (16 countries) ${ }^{a}$ and subregions: annual equivalent variation in per capita income by percentile, 2002-2014, 2002-2009 and 2009-2014b

(Percentages)

\section{A. Latin America}

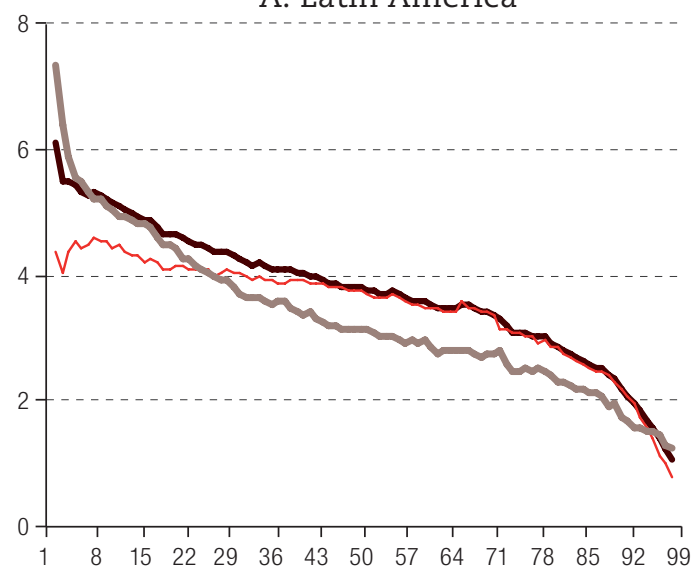

2002-2014
B. Mexico

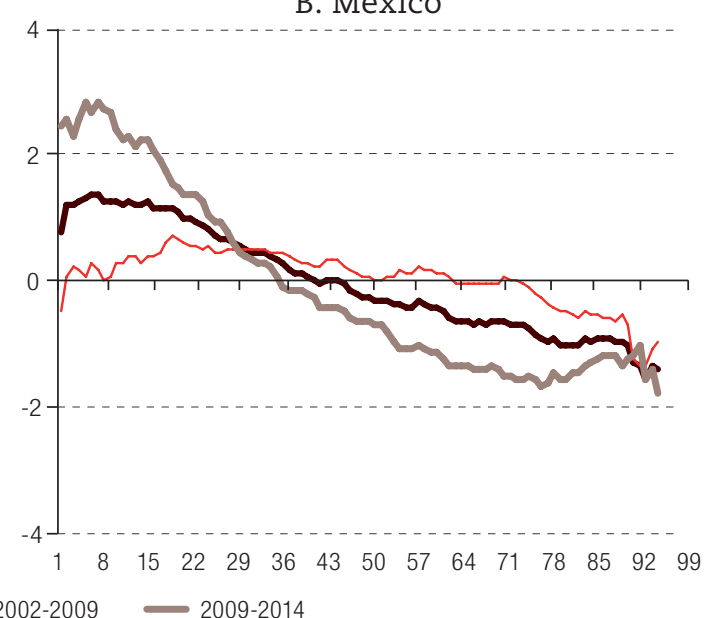


Figure 12 (concluded)

C. Central America

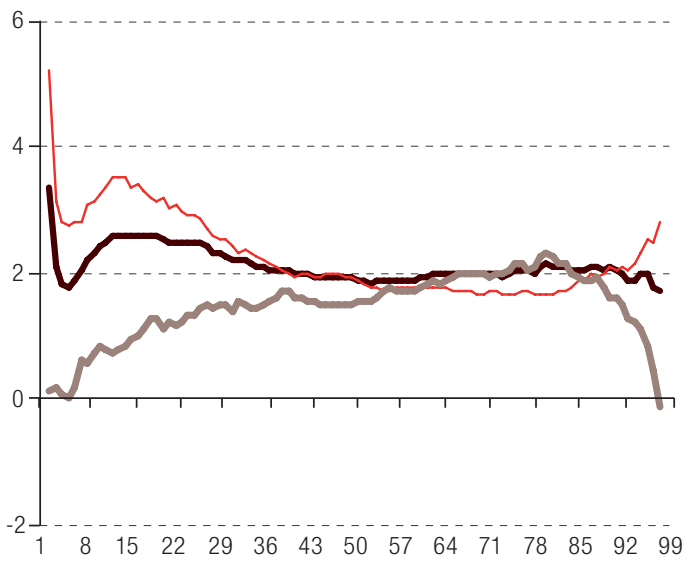

E. Brazil

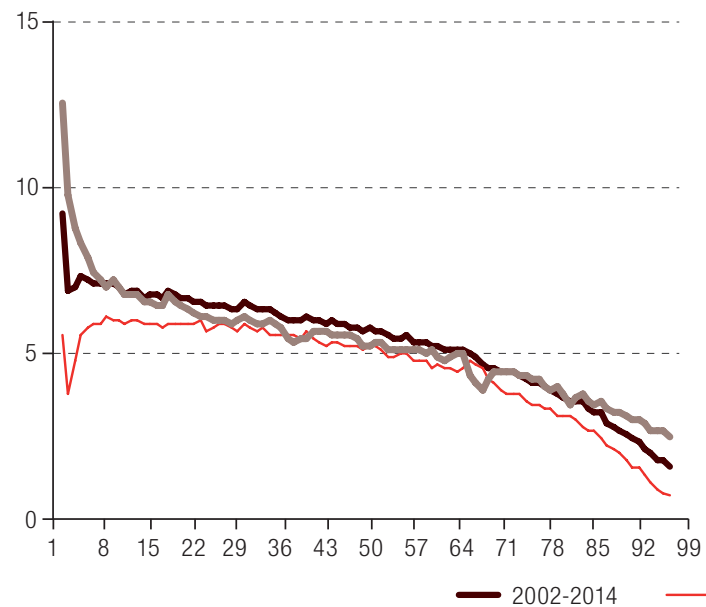

D. Andean Region

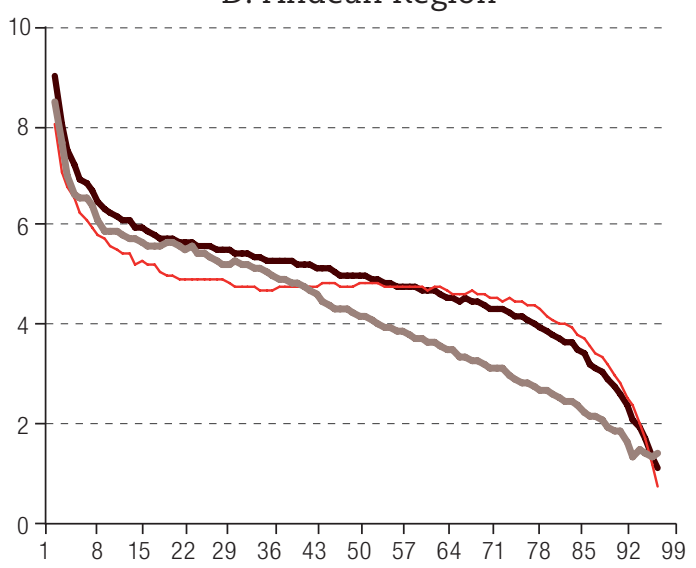

F. Southern Cone

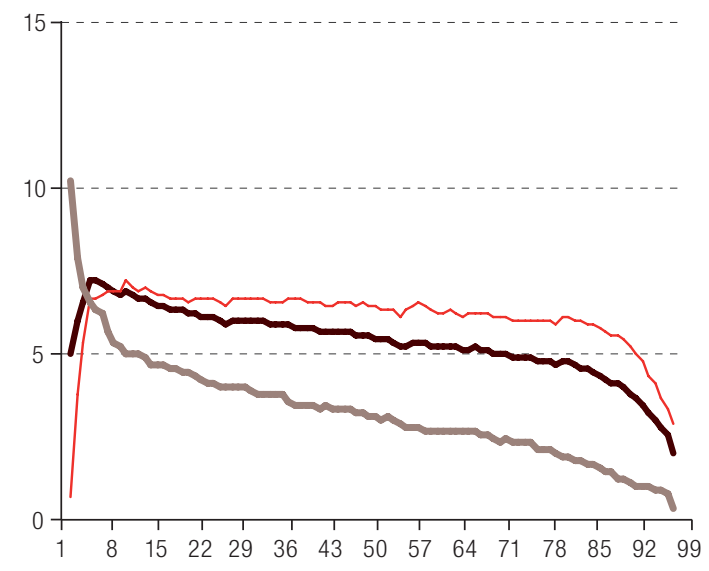

2002-2009 2009-2014

Source: Prepared by the authors, on the basis of household surveys.

a Argentina, Bolivia (Plurinational State of), Brazil, Chile, Colombia, Costa Rica, Dominican Republic, Ecuador, El Salvador, Honduras, Mexico, Panama, Paraguay, Peru, Uruguay and Venezuela (Bolivarian Republic of).

b Growth incidence curves; in purchasing power parity (PPP) at 2011 prices.

It is also instructive to analyse the income variation curves in absolute terms. As discussed in ECLAC (2014b), there are two different concepts underlying the notion of income inequality, involving two different value judgments. One refers to relative inequality, which depends on proportional differences in income, while the other refers to income gaps in absolute terms and is usually called "absolute inequality". The distinction between the two has been almost totally lost in the current empirical studies on inequality, which focus on the relative concept; although in the literature on measuring inequality in the last decade, the quantification of absolute inequality has also been discussed (see Chakravarty and Tyagarupananda, 2009; Bosmans and Cowell, 2010). Absolute inequality will only remain unchanged if household incomes vary by the same amount (not in proportion), which is a very demanding condition. If the income of the wealthiest individuals changes by more in absolute terms, then absolute inequality will increase. Clearly, inequality is much more likely to increase when absolute differences are considered. Between the two visions, neither one is theoretically correct or better than the other; both are acceptable and the choice is ultimately a value judgment (Ravallion, 2004; Atkinson and Brandolini, 2010).

Figure 13 shows the growth incidence curves (GICs) that were previously analysed in relative terms, together with the same variations in absolute terms. In the case of absolute curves, the variation 
in income is increasing in all subregions, except for Mexico. ${ }^{15}$ This means that income grew by more in absolute terms in the richest percentiles than among the poorest in all subregions, even though the absolute increase in income for the latter is proportionately larger. Absolute inequality has thus increased in the Latin American subregions.

\section{Figure 13}

Latin America (16 countries) a and subregions: relative and absolute variation of per capita income by percentile, 2002-2014

(Percentages and PPPC dollars at 2011 prices)

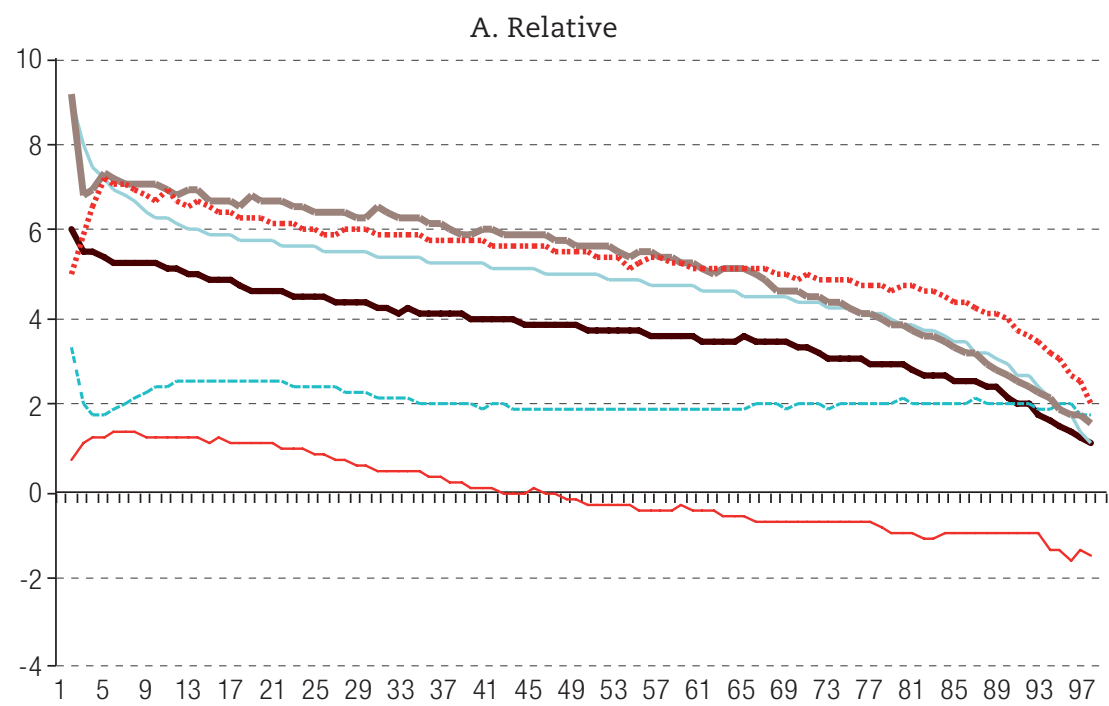

B. Absolute

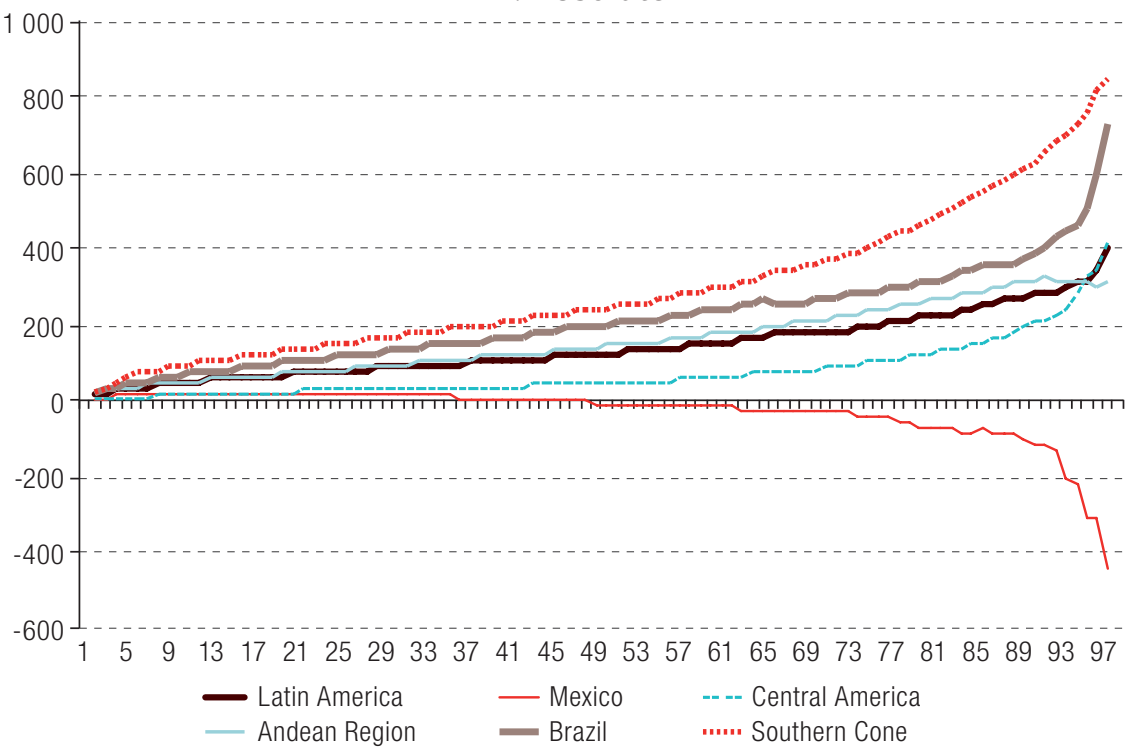

Source: Prepared by the authors, on the basis of household surveys.

a Argentina, Bolivia (Plurinational State of), Brazil, Chile, Colombia, Costa Rica, Dominican Republic, Ecuador, El Salvador, Honduras, Mexico, Panama, Paraguay, Peru, Uruguay and Venezuela (Bolivarian Republic of).

b Growth incidence curves; per capita income in purchasing power parity (PPP) at 2011 prices; annual equivalent relative variation.

c Purchasing power parity.

\footnotetext{
15 In Mexico the income level of high-income recipients has fallen in absolute terms, which is corroborated if the variations between 2012 and 2013 are analysed, and the starting point is changed to 2000. Nonetheless, the drop in income is greater and more generalized in relation to 2014 (in that year, it can be discerned in the median, whereas, in 2012 and 2013, it can only be detected in the last ventile). No more recent surveys are available to determine whether this is due to a survey problem or a more general drop in income in 2014. Without ignoring these elements, a more in-depth study is needed to understand the factors underlying this development.
} 
The different movements occurring in the subregions cause changes in their shares in the regionwide income deciles, as illustrated in figure 14. Brazil has the largest share in all deciles, and its share in the upper deciles increases in 2014. Mexico, in contrast, loses share in the last income levels and shifts towards the low- and middle-income segments. The Andean Region displays smaller movements, with its presence retreating in the first decile while increasing slightly in the last four. The Southern Cone's share in the region's highest income brackets grows strongly, while Central America's presence among the poorest $20 \%$ increases.

\section{Figure 14}

Latin America (five subregions): share in per capita income deciles, 2002 and 2014a (Percentages)

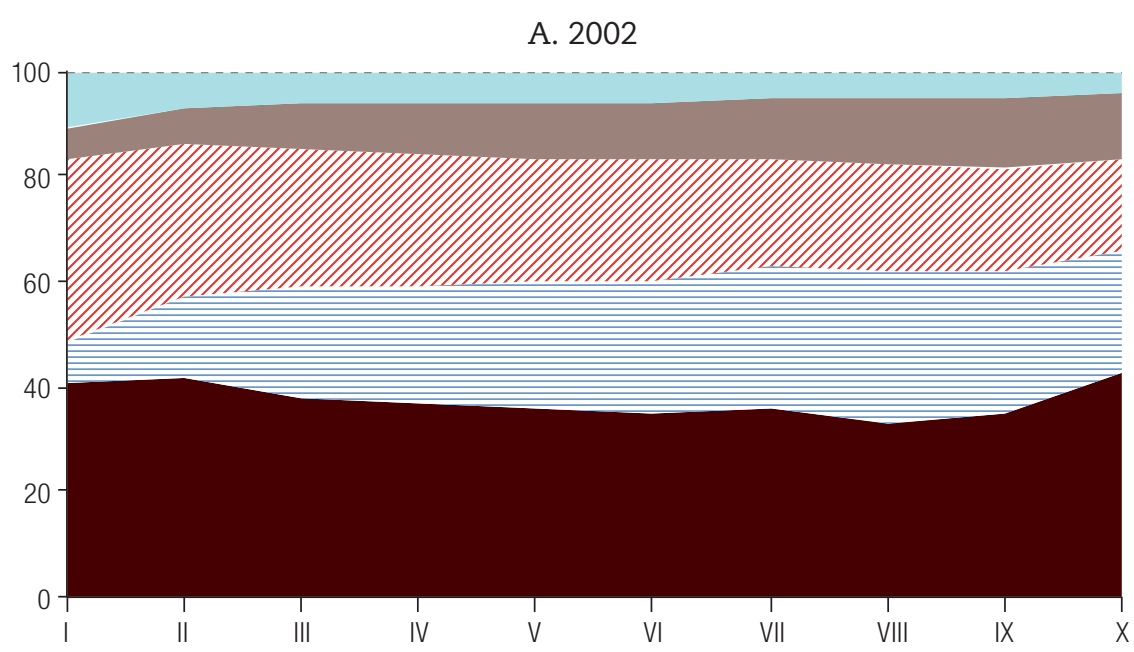

B. 2014

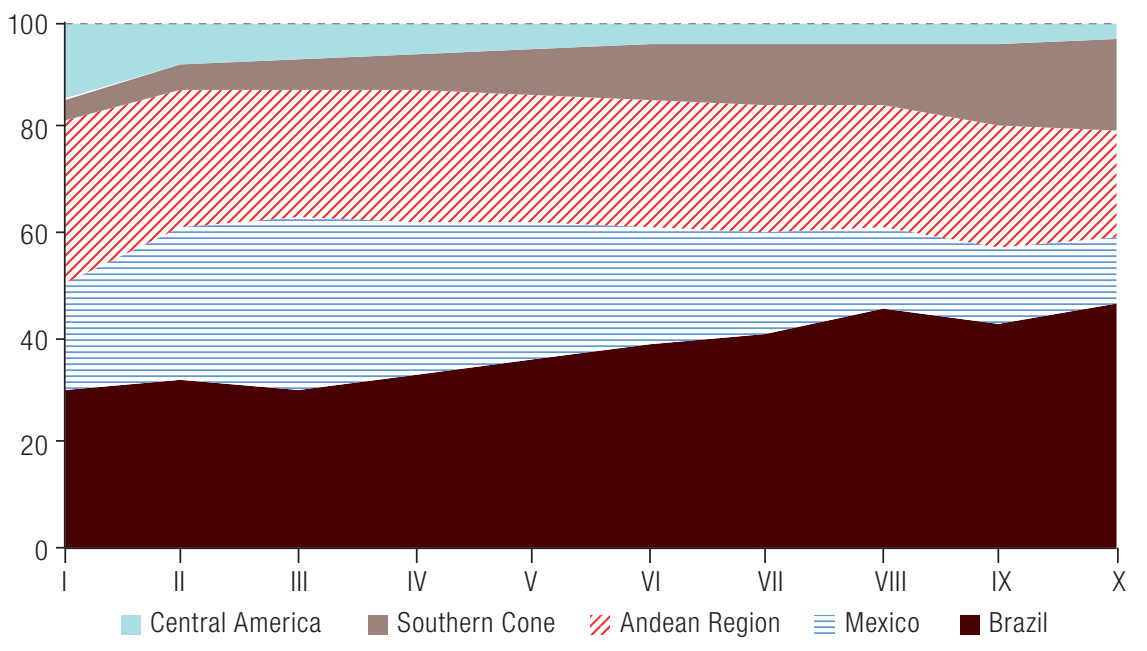

Source: Prepared by the authors, on the basis of household surveys.

a In purchasing power parity (PPP).

Economic growth in the region has slackened in recent years and, as a result, in 2015 labour markets started to show signs of weakness in terms of job creation, loss of dynamism and a rise in unemployment (ECLAC/ILO, 2016). It is unlikely that these more stretched labour markets will be able to drive additional reductions in inequality in less favorable macroeconomic contexts; and, in fact, inequality among the Latin American economies in 2014 does not differ significantly from the previous 
year's levels (ECLAC, 2016). This is a clear sign that the downward trend of earlier years is stalling. Nor does it seem feasible to expect income transfers to reduce inequality further. Firstly, these already have broad coverage in Latin American countries; and, secondly, the fiscal constraints facing the region make it difficult to increase their value, even though they are not large and thus have little redistributive effect, as noted in Amarante and Brun (2016).

A recent paper by Székely and Mendoza (2015) notes that the fate of the region, even in the dimensions most associated with social development, seems to depend heavily on price fluctuations arising from productive specialization; and the recent cycle of declining inequality seems to confirm this. The greater income equality that has been achieved in recent years, especially by boosting the demand for low-skilled workers and hence pushing up their wages, is undoubtedly good news because it means improving the quality of life of millions of people in the region. But this does not yet seem to have established itself as a genuine process of productivity growth that can sustain the increases in equality needed in the long term. Once again, the integration of the social and productive spheres of public policies emerges as a pending task.

\section{Final comments}

Inequality on a global scale has not increased in recent decades. On the contrary, quality evidence now shows that living conditions around the world have become more equal, due mainly to significant income growth in China and, to a lesser extent, in India. At the same time, however, income has become less equally distributed within most countries, especially developing ones. The different forces that may be driving this greater dispersion of income include globalization and trade liberalization processes, which are unfolding alongside technological advances with effects that are hard to isolate. Increasing financialization economies and the concentration of returns to capital further accentuate the income concentration process.

One of the exceptions to this generalized increase in inequality has been Latin America. In the last decade, indicators of income inequality have declined significantly, both in the region as a whole and in its individual countries. A favourable confluence of regional macroeconomic factors also cannot be ignored, such as the rise in commodity prices, which has boosted the region's labour markets, fuelled the demand for unskilled labour and increased wages in the lower part of the distribution. Institutional factors have also been in play, with a differential force in each country. There has also been a greater impetus for redistributive policies, such as non-contributory cash transfers to households with children or older adults, or the strengthening of labour market institutions, such as the minimum wage or collective bargaining. The latest available figures have started to signal faltering economic growth and a weaker labour market, with the declining inequality trend stalling. Thus, the extent to which the region will be able to secure its major income-equality gains is an open question, in particular whether it will be able to regain the path towards greater equality. 


\section{Bibliography}

Acosta, P. and others (2008), "What is the impact of international remittances on poverty and inequality in Latin America?", World Development, vol. 36, No. 1, Amsterdam, Elsevier.

Alvaredo, F. and L. Gasparini (2015), "Recent trends in inequality and poverty in developing countries", Handbook of Income Distribution, A. Atkinson and F. Bourguignon (eds.), vol. 2, Amsterdam, Elsevier.

Amarante, V. and M. Brun (2016), "Cash transfers in Latin America: effects on poverty and redistribution", WIDER Working Paper, No. 2016/136, Helsinki, World Institute for Development Economics Research (UNU-WIDER).

Amarante, V., M. Galván and X. Mancero (2016), "Inequality in Latin America: a global measurement", ECLAC Review, No. 118 (LC/G.2676-P), Santiago, Economic Commission for Latin America and the Caribbean (ECLAC).

Anand, S. and P. Segal (2015), "The global distribution of income", Handbook of Income Distribution, A. Atkinson and F. Bourguignon (eds.), vol. 2, Amsterdam, Elsevier.

(2008), "What do we know about global income inequality?", Journal of Economic Literature, vol. 46, No. 1, Nashville, Tennessee, American Economic Association.

Atkinson, A. B. and A. Brandolini (2010), "On analyzing the world distribution of income", World Bank Economic Review", vol. 24, No. 1, Washington, D.C., World Bank.

Atkinson, A. B. and S. Morelli (2014), "Chartbook of economic inequality", ECINEQ Working Paper Series, No. 2014-324, Society for the Study of Economic Inequality (ECINEQ).

Atkinson, A. B., T. Piketty and E. Sáez (2011), "Top incomes in the long run of history", Journal of Economic Literature, vol. 49, No. 1, Nashville, Tennessee, American Economic Association.

Bartolini, S. and F. Sarracino (2014), "The dark side of Chinese growth: explaining decreasing well-being in times of economic boom", MPRA Paper, No. 57765 [online] https://mpra.ub.uni-muenchen.de/57765/1/ MPRA_paper_57765.pdf.

Bosmans, K. and F. A. Cowell (2010), "The class of absolute decomposable inequality measures", Economics Letters, vol. 109, No. 3, Amsterdam, Elsevier.

Bourguignon, F. (2015), The Globalization of Inequality, Princeton, Princeton University Press.

Brockmann, H. and others (2009), "The China puzzle: falling happiness in a rising economy", Journal of Happiness Studies, vol. 10, No. 4, Springer.

Chakravarty, S. R. and S. Tyagarupananda (2009), "The subgroup decomposable intermediate indices of inequality", Spanish Economic Review, vol. 11, No. 2, Springer.

Cord, L. and others (2016), "Inequality stagnation in Latin America in the aftermath of the global financial crisis", Review of Development Economics, vol. 21, No. 1, Wiley.

Cornia, G. (ed.) (2014), Falling Inequality in Latin America. Policy Changes and Lessons, Oxford, Oxford University Press.

Dollar, D. (2007), "Poverty, inequality, and social disparities during China's economic reform", Policy Research Working Paper, No. 4253, Washington, D.C., World Bank.

ECLAC (Economic Commission for Latin America and the Caribbean) (2016), Social Panorama of Latin America, 2015 (LC/G.2691-P), Santiago.

(2014a), Compacts for Equality: Towards a Sustainable Future (LC/G.2586(SES.35/3)), Santiago.

(2014b), Social Panorama of Latin America, 2014 (LC/G.2635-P), Santiago.

ECLAC/ILO (Economic Commission for Latin America and the Caribbean/International Labour Organization) (2016), Employment Situation in Latin America and the Caribbean, No. 14 (LC/L.4141), Santiago.

Gasparini, L. and others (2012), "Educational upgrading and returns to skills in Latin America: evidence from a supply-demand framework, 1990-2010”, Working Paper, No. 127, La Plata, Center for Distributive, Labour and Social Studies (CEDLAS).

Gasparini, L. and P. Gluzmann (2012), "Estimating income poverty and inequality from the Gallup World Poll: the case of Latin America and the Caribbean", Journal of Income Distribution, vol. 21, No. 1.

Hauser, S. M. and Y. Xie (2005), "Temporal and regional variation in earnings inequality: urban China in transition between 1988 and 1995", Social Science Research, vol. 34, No. 1, Amsterdam, Elsevier.

Jansen, W. and X. Wu (2012), "Income inequality in urban China, 1978-2005", Chinese Sociological Review, vol. 45, No. 1, Taylor \& Francis.

Lakner, C. and B. Milanovic (2016), "Global income distribution: from the fall of the Berlin Wall to the Great Recession”, World Bank Economic Review, vol. 30, No. 2, Washington, D.C., World Bank. 
Maurizio, R. and G. Vázquez (2016), "Distribution effects of the minimum wage in four Latin American countries: Argentina, Brazil, Chile and Uruguay", International Labour Review, vol. 155, No. 1, Wiley.

Meng, X., K. Shen and S. Xue (2013), "Economic reform, education expansion, and earnings inequality for urban males in China, 1988-2009", Journal of Comparative Economics, vol. 41, No. 1, Amsterdam, Elsevier.

Milanovic, B. (2016), Global Inequality: A New Approach for the Age of Globalization, Cambridge, Massachusetts, Harvard University Press. (2005), Worlds Apart: Global and International Inequality 1950-2000, Princeton, Princeton University Press.

Morelli, S., T. M. Smeeding and J. P. Thompson (2015), "Post-1970 trends in within-country inequality and poverty: rich and middle income countries", Handbook of Income Distribution, A. Atkinson and F. Bourguignon (eds.), vol. 2, Amsterdam, Elsevier.

Niño-Zarazúa, M., L. Roope and F. Tarp (2014), "Global interpersonal inequality: trends and measurement", WIDER Working Paper, No. 2014/004, Helsinki, World Institute for Development Economics Research (UNU-WIDER).

OECD (Organization for Economic Cooperation and Development) (2011), Divided We Stand: Why Inequality Keeps Rising, Paris, OECD Publishing.

Piketty, T. (2014), Capital in the 21st Century, Cambridge, Massachusetts, Harvard University Press.

Piketty, T. and E. Sáez (2013), "Top incomes and the great recession: recent evolutions and policy implications", IMF Economic Review, vol. 61, No. 3, Washington, D.C., International Monetary Fund (IMF).

Ravallion, M. (2004), "Competing concepts of inequality in the globalization debate", Policy Research Working Paper, No. 3243, Washington, D.C., World Bank.

Ravallion, M. and S. Chen (2003), "Measuring pro-poor growth", Economic Letters, vol. 78, No. 1, Amsterdam, Elsevier.

Ruiz, N. and N. Woloszko (2016), "What do household surveys suggest about the top $1 \%$ incomes and inequality in OECD countries?", OECD Economics Department Working Papers, No. 1265, Paris, OECD Publishing.

Sicular, T. and others (2007), "The urban-rural income gap and inequality in China", Review of Income and Wealth, vol. 53, No. 1, Wiley.

Székely, M. and P. Mendoza (2015), "Is the decline in inequality in Latin America here to stay?", Journal of Human Development and Capabilities, vol. 16, No. 3, Taylor \& Francis.

Tao Yang, D. and H. Zhou (1999), "Rural-urban disparity and sectoral labour allocation in China", The Journal of Development Studies, vol. 35, No. 3, Taylor \& Francis.

World Bank (2015), Purchasing Power Parities and the Real Size of World Economies. A Comprehensive Report of the 2011 International Comparison Program, Washington, D.C.

Xie, Y. and X. Zhou (2014), "Income inequality in today's China", Proceedings of the National Academy of Sciences, vol. 111, No. 19, National Academy of Sciences.

Zhou, X. (2014), "Increasing returns to education, changing labour force structure and the rise of earnings inequality in urban China, 1996-2010", Social Forces, vol. 93, No. 2, Oxford University Press. 


\section{Annex A1}

Table A1.1

Latin America (16 countries): surveys used to determine regional inequality

\begin{tabular}{llll}
\hline \multicolumn{1}{c}{ Country } & 2002 & 2009 & 2014 \\
\hline Argentina & 2002 & 2009 & 2012 \\
\hline Bolivia (Plurinational State of) & 2002 & 2009 & 2013 \\
\hline Brazil & 2002 & 2009 & 2014 \\
\hline Chile & 2003 & 2009 & 2013 \\
\hline Colombia & 2002 & 2009 & 2014 \\
\hline Costa Rica & 2002 & 2009 & 2014 \\
\hline Dominican Republic & 2002 & 2009 & 2014 \\
\hline Ecuador & 2002 & 2009 & 2014 \\
\hline El Salvador & 2001 & 2009 & 2014 \\
\hline Honduras & 2002 & 2009 & 2010 \\
\hline Mexico & 2002 & 2008 & 2014 \\
\hline Panama & 2002 & 2009 & 2014 \\
\hline Peru & 2001 & 2009 & 2014 \\
\hline Paraguay & 2001 & 2009 & 2014 \\
\hline Uruguay & 2002 & 2009 & 2014 \\
\hline Venezuela (Bolivarian Republic of) & 2002 & 2009 & 2013 \\
\hline
\end{tabular}

Source: Prepared by the authors, on the basis of household surveys.

Table A1.2

Latin America (16 countries): weight of each country in income and population (Percentages)

\begin{tabular}{|c|c|c|c|c|c|c|}
\hline \multirow{2}{*}{ Country } & \multicolumn{2}{|c|}{2002} & \multicolumn{2}{|c|}{2009} & \multicolumn{2}{|c|}{2014} \\
\hline & Population & Income (PPP) & Population & Income (PPP) & Population & Income (PPP) \\
\hline Argentina & 5.4 & 6.4 & 4.8 & 8.5 & 4.7 & 7.5 \\
\hline Bolivia (Plurinational State of) & 1.9 & 1.0 & 2.0 & 1.2 & 2.0 & 1.2 \\
\hline Brazil & 37.4 & 41.6 & 37.6 & 41.8 & 37.2 & 43.3 \\
\hline Chile & 3.4 & 4.1 & 3.3 & 4.0 & 3.2 & 4.2 \\
\hline Colombia & 8.7 & 5.5 & 8.6 & 5.7 & 8.5 & 6.1 \\
\hline Costa Rica & 0.9 & 0.9 & 0.9 & 0.9 & 0.9 & 0.9 \\
\hline Dominican Republic & 1.4 & 0.8 & 1.2 & 0.6 & 1.2 & 0.6 \\
\hline Ecuador & 1.8 & 1.3 & 2.8 & 1.6 & 3.0 & 1.8 \\
\hline El Salvador & 1.5 & 0.6 & 1.6 & 0.6 & 1.5 & 0.5 \\
\hline Honduras & 22.3 & 23.3 & 21.2 & 19.0 & 22.0 & 18.1 \\
\hline Mexico & 0.7 & 0.6 & 0.7 & 0.6 & 0.7 & 0.7 \\
\hline Panama & 1.2 & 0.9 & 1.2 & 0.8 & 1.2 & 1.1 \\
\hline Peru & 5.9 & 3.2 & 6.0 & 3.8 & 5.8 & 4.0 \\
\hline Paraguay & 1.8 & 1.6 & 1.9 & 1.7 & 1.9 & 1.5 \\
\hline Uruguay & 0.6 & 0.8 & 0.7 & 0.9 & 0.6 & 0.9 \\
\hline Venezuela (Bolivarian Republic of) & 5.4 & 7.3 & 5.5 & 8.3 & 5.5 & 7.8 \\
\hline
\end{tabular}

Source: Prepared by the authors, on the basis of household surveys.

Note: PPP: purchasing power parity. 
